\title{
The Use of Surface-Modified Nanocrystalline Cellulose Integrated Membranes to Remove Drugs from Waste Water and as Polymers to Clean Oil Sands Tailings Ponds
}

\author{
John Jackson ${ }^{1, *}$, Ali Moallemi ${ }^{2}$, Mu Chiao $^{2}$ and David Plackett ${ }^{1}$ \\ 1 Faculty of Pharmaceutical Sciences, University of British Columbia, 2405 Wesbrook Mall, \\ Vancouver, BC V6T 1Z3, Canada; davidplackett@gmail.com \\ 2 Department of Biomedical Engineering, University of British Columbia, Vancouver, BC V6T 1Z3, Canada; \\ ali.moallemi91@gmail.com (A.M.); muchiao@mech.ubc.ca (M.C.) \\ * Correspondence: jackson@mail.ubc.ca
}

check for updates

Citation: Jackson, J.; Moallemi, A.; Chiao, M.; Plackett, D. The Use of Surface-Modified Nanocrystalline Cellulose Integrated Membranes to Remove Drugs from Waste Water and as Polymers to Clean Oil Sands Tailings Ponds. Polymers 2021, 13, 3899. https://doi.org/10.3390/ polym13223899

Academic Editor: Loreto García Fernández

Received: 11 October 2021

Accepted: 8 November 2021

Published: 11 November 2021

Publisher's Note: MDPI stays neutral with regard to jurisdictional claims in published maps and institutional affiliations.

Copyright: (c) 2021 by the authors. Licensee MDPI, Basel, Switzerland. This article is an open access article distributed under the terms and conditions of the Creative Commons Attribution (CC BY) license (https:// creativecommons.org/licenses/by/ $4.0 /)$.

\begin{abstract}
There is an urgent environmental need to remediate waste water. In this study, the use of surface-modified nanocrystalline cellulose (CNC) to remove polluting drugs or chemicals from waste water and oil sands tailing ponds has been investigated. CNC was modified by either surface adsorbing cationic or hydrophobic species or by covalent methods and integrated into membrane water filters. The removal of either diclofenac or estradiol from water was studied. Similar non-covalently modified CNC materials were used to flocculate clays from water or to bind naphthenic acids which are contaminants in tailing ponds. Estradiol bound well to hydrophobically modified CNC membrane filter systems. Similarly, diclofenac (anionic drug) bound well to covalently cationically modified CNC membranes. Non-covalent modified CNC effectively flocculated clay particles in water and bound two naphthenic acid chemicals (negatively charged and hydrophobic). Modified CNC integrated into water filter membranes may remove drugs from waste or drinking water and contaminants from tailing ponds water. Furthermore, the ability of modified CNC to flocculate clays particles and bind naphthenic acids may allow for the addition of modified CNC directly to tailing ponds to remove both contaminants. CNC offers an environmentally friendly, easily transportable and disposable novel material for water remediation purposes.
\end{abstract}

Keywords: water treatment; nanocrystalline cellulose; membrane filtration; cationic polymer; drugs; oil sands

\section{Introduction}

There is an increasing global awareness of the need to clean up waste water. Contaminants range from micropollutants such as household-discarded drugs to huge tailings ponds next to oil sand bitumen extraction facilities. Whilst drugs are only present at very low concentrations, they may have pronounced cumulative effects for both aquatic life and humans. According to the World Health Organization (WHO), nanogram-level concentrations of pharmaceuticals in drinking water raised concerns regarding the potential risks to human health [1-3]. The potential environmental impact of huge volumes of contaminated water in tailing ponds is obvious. Current methods to remove drugs from water or to remediate tailings ponds are ineffective. There is an unmet need for systems that themselves do not create alternative problems like high energy use, fouling, non-degradable clean up materials, transportation or intense maintenance issues.

The pollution of water is a major environmental issue. For systems that adsorb and remove pollutants, it is preferable for the adsorbate to have high surface areas to maximize direct adsorption, and to be inexpensive and biodegradable. Considerable attention has been paid to the potential use of nanomaterials in environmental remediation science due to the high surface area to volume ratio, easily functionalized surfaces for specific trapping 
and easy transport [4,5]. Cellulose, and in particular nanocellulose, is such a material and has the added advantage of being easily surface derivatized to create surfaces for specific adsorbing purposes [6].

Nanocrystalline cellulose (CNC) is extracted from wood biomass by acidic extraction methods producing nanosized cellulose rods with a very high surface to volume ratio. Due to this large surface area, high aspect ratio, and strength, $\mathrm{CNC}$ is being investigated as a nanocomposite material. A thorough review of the chemical properties of $\mathrm{CNC}$ is available from Habibi et al. [7]. Nanocrystalline cellulose, either native or surface modified, has been proposed for use in removing metal, oil and pharmaceutical contaminants from water [8-11]. Because of the ability to bind drugs, CNC has also been used in formulations for drug delivery underlining the potential for the material to sequester drugs from polluted waters [12,13].

On a micropollutant front, there are numerous types of drugs disposed of everyday down household sewerage systems. Most drugs are degraded in the activated sludge phase of sewage treatment [14,15]. However, some drugs are only partially degraded and have significant biological activity. These include the heavily prescribed and disposed of group called non-steroidal anti-inflammatories (like ibuprofen, naproxen and diclofenac) and the hormones based on estrogen [15-17]. Indeed, diclofenac and estradiol are known to be the most important disposed drugs on the EU 2015 watch list for pharmaceutical contaminants [16]. The sewage sludge degradation of estradiol is poor and diclofenac persists at high levels after sewage treatment $[15,16]$. These agents are harmful to numerous biological species at low concentrations and it should be remembered that in many waterrestricted countries, household drinking water is recycled and provided back to household water supplies raising the risk of cumulative exposure to low drug concentrations and associated toxicity. There exists a need to remove undegraded drugs like estradiol and diclofenac after the activated sludge process (before efflux into rivers or the ocean) or to treat recycled drinking water before release from household taps. In terms of macropollutants, the process of extracting bitumen from the Alberta oil sands requires the use of large amounts of heated water and generates huge volumes of polluted waste water which are pumped into tailings ponds. These liquids contain sand, clay, residual bitumen and toxic complex hydrocarbons (mostly naphthenic acids). Following a rapid sedimentation of large particulates like sand, the residual clay and bitumen do not settle quickly and create an escalating environmental problem centered on the inability to reclaim the water and land. By 2015, less than $2 \%$ of tailings ponds had been reclaimed with untreated tailings ponds taking decades to clear [18].

Despite extensive research no single simple method yet exists to address these problems which are projected to grow as oil extraction expands over the next 50 years. Most efforts focus on the use of polymer flocculants to disrupt the repulsive forces between clay particles that keep them in suspension [19-21]. However, the composition of tailings clays and their suspension in the tailings water is complex, highlighted by the presence of various clay types, their ability to swell and hold water and potential interactions of clays with bitumen which may mask their surface charge and flocculation potential. Many clay particles are negatively charged at neutral $\mathrm{pH}$ and become even more negative at high $\mathrm{pH}$ such as tailings ponds at $\mathrm{pH}$ of approximately 8.5 [19]. The widely -used polymer Percol 727 (a high molecular weight polyacrylamide (PAM)) is ineffective at flocculating smaller clay particles such as montmorillonites which have very high specific surface areas and massive cation exchange capacities [19-22]. PAM-flocculated tailings liquids still may have $3 \%$ residual amounts of suspended clays where the limit for water disposal is $0.5 \%$ making further treatments necessary to remove these highly negatively charged species.

The is an unmet need for an inexpensive cationic material capable of flocculating and removing these small negatively charged clays like montmorillonites. Other workers have had limited success in flocculating kaolin clays using cellulose [23,24]. In these studies, the use of cationically modified nanocellulose (CTAC-CNC) to flocculate Cloisite (a commercial montmorillonite) clay at $\mathrm{pH} 8.5$ was investigated and an effective flocculation of clay with this agent was observed. 
Aliphatic and aromatic naphthenic acids are the principal small molecule contaminants in tailings ponds [25-29]. These agents are corrosive to all engineering equipment and highly toxic to aquatic life and potentially to humans if they reach high concentrations in rivers [30-32]. Naphthenic acids do not degrade easily by natural methods and accelerated oxidation using ozone or oxygen radical forming agents are only partially successful [30]. A variety of methods have been investigated for the removal of these chemicals with limited success [25-30].

Nanocrystalline cellulose (CNC) is the smallest extractable subunit of cellulose from inexpensive and abundant wood biomass. $\mathrm{CNC}$ has the benefit of a negative surface charge and a huge surface to volume ratio, allowing for high levels of surface modification. Previous studies have demonstrated that both chemically modified and unmodified CNC may bind various drugs with the intention of using the biocompatible CNC as a controlled drug release system [12]. The ability of CNC to bind and hold either charged or hydrophobic drugs hints at their potential to be used to remove unwanted chemical species (like drugs) from waste water. The overall objective of this study was to investigate the use of either cationic or hydrophobically modified CNC for various environmentally significant purposes. Specifically, these purposes include removing drugs from waste water and removing clays and organic contaminants from oil sands tailings ponds. Accordingly, $\mathrm{CNC}$ was integrated into membrane filters to remove estradiol or diclofenac from water and the modified CNC materials were used to flocculate clays and bind naphthenic acids. The novelty of these studies lies in the potential use of an inexpensive, ecologically compatible material $(\mathrm{CNC})$ as an easy to use material for environmental remediation purposes.

\section{Materials}

CNC was provided by Alberta Innovates (Edmonton, AB, Canada) as a suspension in water at $1.8 \% w / v$. All solvents were HPLC grade and obtained from Thermo Fisher Scientific (Ottawa, ON, Canada). Millipore filtration centrifuge tubes (0.22 um) were obtained from Millipore Canada (Oakville, ON, Canada). Large filtration units and filters (McMaster-Carr code 1354 N12 $0.22 \mu \mathrm{m}$ ) were obtained from McMaster-Carr (Douglasville, GA, USA). Cloisite $(\mathrm{Na}+$ ) clay samples were supplied by Southern Clays (Gonzales, TX, USA). All plasticware was supplied by Sarstedt (St Leonard, QC, Canada). All other reagents including the drugs estradiol (beta-estradiol) and diclofenac, naphthenic acids (4-(-2-naphthyloxy) butanoic acid and 4-(4-tert butyl phenyl) butanoic acid), conjugation reagents, etc. were purchased from Sigma Aldrich (Oakville, ON, Canada).

\section{Methods}

CNC was covalently modified using dioctenyldimethyl succinic anhydride (DDSA) (hydrophobic surface) or using polydiallyl dimethyl ammonium chloride (PDMC) (cationic surface).

\subsection{Dioctenyldimethyl Succinic Anhydride-Nanocrystalline Cellulose (DDSA-CNC) Synthesis}

A sample of CNC (2 g) was dispersed into $50 \mathrm{~mL}$ of distilled water and then centrifuged at $3500 \mathrm{rpm}$ for $10 \mathrm{~min}$. After removing the supernatant liquid, acetone $(30 \mathrm{~mL})$ was added, and the mixture centrifuged before the supernatant acetone was discarded. This process was then repeated twice. After discarding the acetone, the CNC was solventexchanged into $N, N$-dimethylformamide (DMF) by adding DMF $(30 \mathrm{~mL})$ into each of two centrifuge tubes. After shaking for $5 \mathrm{~min}, 20 \mathrm{~mL}$ of the mixture was transferred into each of two further centrifuge tubes. Then, $20 \mathrm{~mL}$ of acetone was added to each tube and the tubes were then centrifuged at $3000 \mathrm{rpm}$ for $10 \mathrm{~min}$ before discarding the supernatant liquid. In the next step, DMF $(50 \mathrm{~mL})$ was added and mixed before the supernatant was poured off into a beaker and heated at $85^{\circ} \mathrm{C}$ for about $15 \mathrm{~min}$ to ensure acetone evaporation. Then, dimethylaminopyridine (DMAP) (0.5 g) was added. The DDSA reactant (2 g) was mixed with $10 \mathrm{~mL} \mathrm{DMF}$ and this solution was added to the CNC dispersion containing DMAP. After $4 \mathrm{~h}$ at room temperature, the dispersion was transferred to a filter flask with $140 \mathrm{~mL}$ 
acetone. A sample of this dispersion $(40 \mathrm{~mL})$ was centrifuged at $3400 \mathrm{rpm}$ for 5 min before discarding the supernatant. This process was repeated twice before the supernatant was discarded and the modified CNC allowed to air dry for $24 \mathrm{~h}$. This method is similar to that of Leszczyńska et al. [33].

\subsection{Polydiallyl Dimethyl Ammonium Chloride (PDMC)-CNC Synthesis}

CNC (2 g) was dispersed in $100 \mathrm{~mL}$ of distilled water and $100 \mathrm{~mL}$ of a $20 \% w / v$ PDMC solution was then added with stirring for $24 \mathrm{~h}$. In the next step sodium chloride $(20 \mathrm{~g})$ was stirred into the CNC suspension for a further $24 \mathrm{~h}$. After centrifugation at $620 \mathrm{rpm}$ for $1 \mathrm{~h}$, the supernatant was discarded. The suspension was then washed with distilled water by way of centrifugation, which was repeated five times and the modified CNC sediment was then collected. This sediment was freeze-dried for $24 \mathrm{~h}$ to yield a final PDMC-CNC product. This method is similar to that of Huang et al. [34]

\subsection{Preparation of Cationic CNC (CTAC-CNC) or Hydrophobic CNC (CTAB-CNC) (Both Non-Covalent Methods)}

Cationic CNC (CTAC-CTAC-CNC) was made by incubating $200 \mathrm{~mL}$ of CNC $(18 \mathrm{mg} / \mathrm{mL}$ water) with 3-chloro hydroxy propyl trimethyl ammonium chloride (CTAC) in the presence of excess sodium hydroxide for $12 \mathrm{~h}$. The mixture was centrifuged at $2000 \times g$ in a Beckman table top swinging bucket centrifuge for $30 \mathrm{~min}$ and the CNC pellet was resuspended and washed four times with centrifugation and made up to a final concentration of $15 \mathrm{mg} / \mathrm{mL}$ in water. Hydrophobic CNC was manufactured by incubating $200 \mathrm{~mL}$ of CNC $(18 \mathrm{mg} / \mathrm{mL})$ with cetyl trimethyl ammonium bromide (CTAB) for $30 \mathrm{~min}$ followed by centrifugation and washing. For studies with estradiol, CTAB was used at $10 \mathrm{mM}$ and for naphthenic acid studies CTAB was used at either 7.5 or $15 \mathrm{mM}$. For estradiol binding studies the CTAB-CNC was used at $15 \mathrm{mg} / \mathrm{mL}$ and for naphthenic acid binding studies it was used at either $7.5 \mathrm{mg} / \mathrm{mL}$ or $15 \mathrm{mg} / \mathrm{mL}$.

\subsection{Drug or Contaminant Analysis}

Diclofenac was measured using UV/VIS spectrophotometric methods at $275 \mathrm{~nm}$. Briefly this method involves measuring the absorbance of light at $275 \mathrm{~nm}$ using a Cary 50 spectrometer (Agilent, Santa Clara, CA, USA). A set of calibration standards in the $0-10 \mu \mathrm{g} / \mathrm{mL}$ range was initially measured to create a linear standard curve. and estradiol was measured using high-performance liquid chromatography (Waters Acquity system) with a mobile phase of 50\% water: $50 \%$ acetonitrile a flow rate of $1 \mathrm{~mL}$ per minute and detection at $280 \mathrm{~nm}$ as previously described [35]. Both drugs gave linear calibration curves in the $0-10 \mu \mathrm{g} / \mathrm{mL}$ range with correlation coefficients of 0.99 . The naphthenic acid contaminants were analyzed using UV/VIS methods with detection at $362 \mathrm{~nm}$. Calibration curves were linear in the $0-50 \mu \mathrm{g} / \mathrm{mL}$ range with correlation coefficients great than 0.985 .

\subsection{Filtration}

For small-scale membrane filtration, $50 \mathrm{~mL}$ centrifuge tubes with $0.22 \mu \mathrm{m}$ Millipore Steriflip filters (Oakville, ON, Canada) were used as shown in Figure 1a. We suspended 5, 10 or $20 \mathrm{mg}$ of derivatized CNC in 5-10 mL of water and dispersed it using an ultrasonic tip disruptor sufficient to fully disperse the material without heating. The nanosuspension was then poured onto the filter and vacuum applied until all the material had filtered. The membrane was then washed three times using $5 \mathrm{~mL}$ of water under a vacuum and all the filtered liquid was discarded. The filter was then ready for application of a drug solution. Measured using optical density at $300 \mathrm{~nm}$, this method removed 100\% of CNC from the water so that it was bound to the membrane filter. Five $\mathrm{mL}$ of drug solution $(2 \mu \mathrm{g} / \mathrm{mL}$ estradiol or diclofenac) was then added to the membrane and the solution was filtered through under vacuum. The filtered solution was then saved for drug analysis and the amount bound was calculated by subtracting the amount of drug in the filtered solution from the original drug amount in solution applied to the membrane filter. 


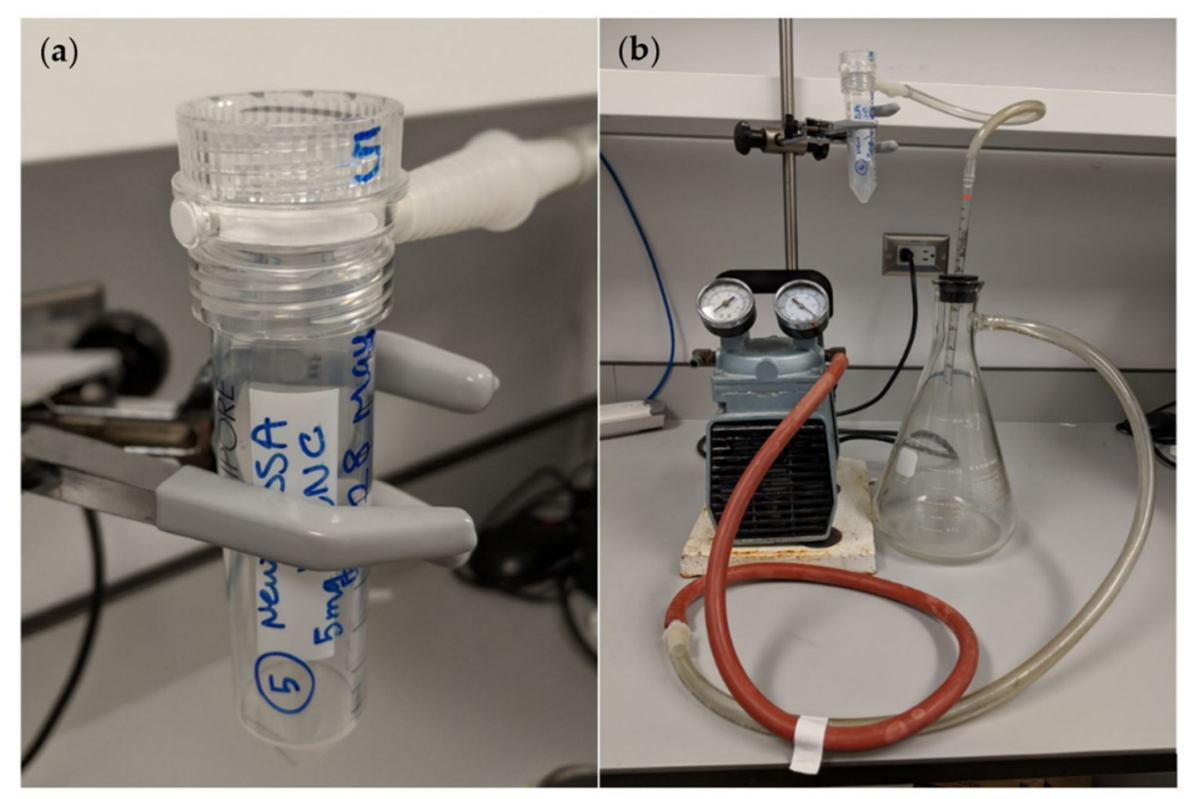

Figure 1. (a) Millipore Steriflip filter $(0.22 \mu \mathrm{m})$. (b) Setup for the small-scale filtration.

For larger-scale filtration, $2 \mathrm{~L}$ capacity systems were used as shown in Figure $1 \mathrm{~b}$. Initially a $1 \mu \mathrm{m}$ filter was tried in a household "Rainfresh" TM ${ }^{\mathrm{TM}}$ uer the counter inexpensive system. However, when CNC was filtered through only $40 \%$ was bound to the filter as measured by the reduction in optical density at $300 \mathrm{~nm}$. A more expensive system (McMaster-Carr code 1354 N12 polypropylene plastic filter) with a $0.2 \mu \mathrm{m}$ filter was then used and this removed $100 \%$ of the CNC from the water. Two grams of CNC was dispersed in water using an ultrasonic tip disruptor and made up to $2 \mathrm{~L}$ of water. Both the interior and exterior sections of the filter were filled with water. This solution was filtered through the apparatus under vacuum and then vacuum washed three times with $2 \mathrm{~L}$ of water.

\subsection{Loading of CNC on to Small Scale Filters}

Using unmodified $\mathrm{CNC}$ at $1 \mathrm{mg} / \mathrm{mL}, 5 \mathrm{~mL}$ was sequentially filtered through the small filter and the time required for full filtration was recorded.

\subsection{Zeta Potential Measurments}

Zeta potential was measured using a Zetasizer instrument (Malvern Instruments, Malvern, Worcester, England)

\subsection{Drug Binding Studies}

For binding of diclofenac, the PDMC-CNC was loaded onto the small-scale filter either at $5 \mathrm{mg}$ or $20 \mathrm{mg}$ total per filter. We passed $5 \mathrm{~mL}$ of diclofenac at $2 \mu \mathrm{g} / \mathrm{mL}$ through the filter and the amount of drug in the filtered liquid (unbound fraction) was analyzed and discarded. The process was repeated. For large-scale filtration $2 \mathrm{~g}$ of the PDMC-modified $\mathrm{CNC}$ was loaded onto the filter. We filtered $2 \mathrm{~L}$ of diclofenac at $2 \mu \mathrm{g} / \mathrm{mL}$ through the system under vacuum and the filtered liquid was analyzed for unbound drug content.

For estradiol binding with $\mathrm{CTAB}-\mathrm{CNC}$, the $\mathrm{CTAB}$ was used at $10 \mathrm{mM}$ for modification and $25 \mathrm{mg}$ of CTAB-CNC was integrated into the small-scale membrane and repeated $1 \mathrm{~mL}$ volumes of estradiol at $2 \mu \mathrm{g} / \mathrm{mL}$ were filtered. In a second experiment only $5 \mathrm{mg}$ of CTAB-CNC was integrated into the membrane and larger volumes $(5 \mathrm{~mL})$ of estradiol $(2 \mu \mathrm{g} / \mathrm{mL})$ were filtered.

The DDSA-CNC was loaded onto the small filter at $5 \mathrm{mg}$ or $10 \mathrm{mg}$ total per filter and at $2 \mathrm{~g}$ onto the large-scale filter. Five $\mathrm{mL}$ (small scale) or $2 \mathrm{~L}$ (large scale) of estradiol at $2 \mu \mathrm{g} / \mathrm{mL}$ were filtered through the filters and the amount of unbound drug analyzed by HPLC methods as described in the Methods section. 


\subsection{Clay Flocculation Experiments}

Cloisite clay was suspended in water at $10 \mathrm{mg} / \mathrm{mL}$ using ultrasonic tip sonication for $2 \mathrm{~min}$ without heating. This process was repeated twice. The resulting suspension only sedimented if the centrifuge force rose above $600 \mathrm{rpm}$ (approx. $70 \times g$ ). Two $\mathrm{mL}$ of the clay suspension was added to a $5 \mathrm{~mL}$ tube followed by various volumes of the CTAC-CNC suspension at $15 \mathrm{mg} / \mathrm{mL}$. These volumes ranged from 25 to $600 \mu \mathrm{L}$ and all tubes were topped up with water to a final volume of $2.6 \mathrm{~mL}$. Tubes were shaken and left to stand for $5 \mathrm{~min}$ followed by analysis of the optical density (A $500 \mathrm{~nm}$ ) of the top $0.7 \mathrm{~mL}$ in a UV/VIS spectrophotometer.

\subsection{Naphthenic Acid Binding to CNC}

Naphthyloxy butanoic acid or butyl phenyl butanoic acid were dissolved in water ( $\mathrm{pH}$ adjusted to 8.3 using very dilute sodium hydroxide) at $125 \mu \mathrm{g} / \mathrm{mL}$ and serial diluted. CTABor CTAC-modified CNC was added at either 7.5 or $15 \mathrm{mg} / \mathrm{mL}$. For CTAB experiments, sodium chloride at $10 \mathrm{mM}$ was added to facilitate sedimentation under centrifugation. After $60 \mathrm{~min}$, the $\mathrm{CNC}$ was pelleted by high-speed centrifugation and the unbound fraction of the naphthenic acids measured by UV/VIS spectroscopy.

\section{Results}

\subsection{Filtration Methods}

The apparatus for small- and large-scale membrane filtration is shown separately in Figures 1 and 2. All forms of CNC were captured on the $0.22 \mu \mathrm{m}$ small-scale Millipore filter as observed by the optical density $(A 500 \mathrm{~nm}$ ) of the filtrate solution which was zero and clear. It was possible to filter numerous $\mathrm{CNC}$ suspension volumes (each containing $5 \mathrm{mg}$ weights of $\mathrm{CNC}$ ) through the filter with the accumulation of $\mathrm{CNC}$ on the filter having little effect on the filtration time, which was about $3 \mathrm{~min}$ for $5 \mathrm{~mL}$ of suspension $(1 \mathrm{mg} / \mathrm{mL})$ as shown in Figure 3. Even after 10 filtrations and $50 \mathrm{mg}$ of $\mathrm{CNC}$ the membrane was unclogged and still able to integrate more $\mathrm{CNC}$.

\subsection{Binding of Estradiol to CTAB-CNC Integrated Small-Scale Membranes}

When $25 \mathrm{mg}$ of CTAB-CNC was integrated into the filter there were high levels of estradiol removal from water, as seen by the high levels of binding in Figure 4. Binding refers to the removal of a certain percentage of the applied drug. The $\%$ drug bound decreased from almost $100 \%$ on the first filtration run to a little under $60 \%$ bound after 22 repeated filtrations as seen in Figure 4a. The decreased binding with each run was approximately the same over the course of the 22 filtrations (approximately $2 \%$ decrease per filtration run). When only $5 \mathrm{mg}$ of CTAB-CNC was loaded into the membrane filter and $5 \mathrm{~mL}$ volumes of estradiol at $2 \mu \mathrm{g} / \mathrm{mL}$ were filtered slightly lower levels of drug binding were observed as seen in Figure $4 \mathrm{~b}$. Although almost $100 \%$ of the drug was removed on the first filtration run, the \% drug bound on each subsequent run dropped by approximately $16 \%$ for each of the next 5 runs with less than $20 \%$ of the loaded drug removed on each run after that. Using 20 repeated filtrations of $1 \mathrm{~mL}$ volumes of drug solution (total of $40 \mu \mathrm{g}$ of drug applied to filter) to filters containing $25 \mathrm{mg}$ of $\mathrm{CTAB}-\mathrm{CNC}$, the $60 \%$ drug binding level was maintained. However, for filters containing $5 \mathrm{mg}$ CTAB-CNC after four filtrations of $5 \mathrm{~mL}$ (total $40 \mu \mathrm{g}$ of drug) there was less drug binding ( $50 \%$ binding). At the end of estradiol filtration experiments, the addition and filtration of $5 \mathrm{~mL}$ of ethanol through the drug-adsorbed CNC-integrated membrane allowed for 100\% recovery of the estradiol. 


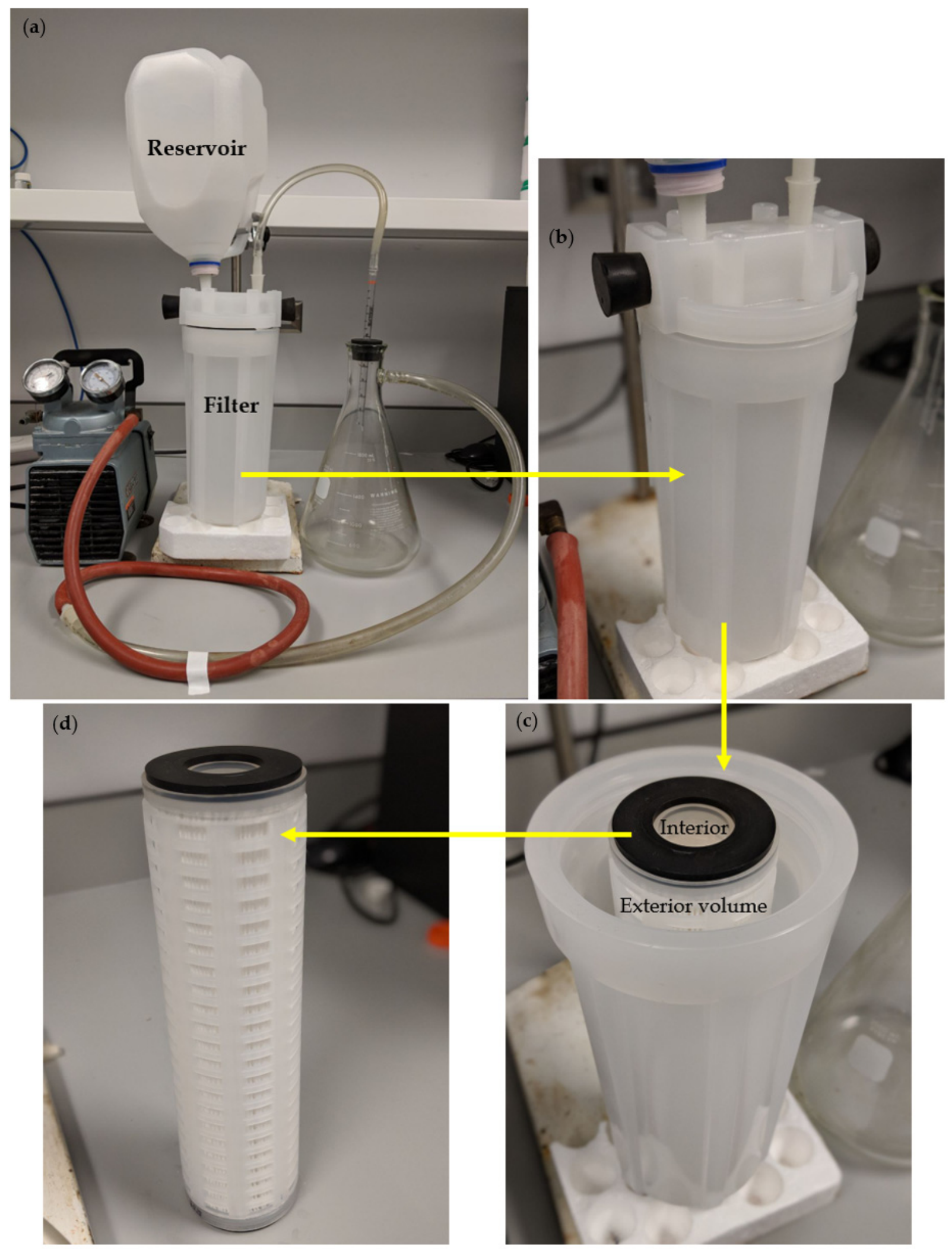

Figure 2. The setup for the large-scale (commercial) filter. (a): full system, (b): sealed filter chamber, (c): inner chamber and (d) $0.2 \mu \mathrm{m}$ filter. 


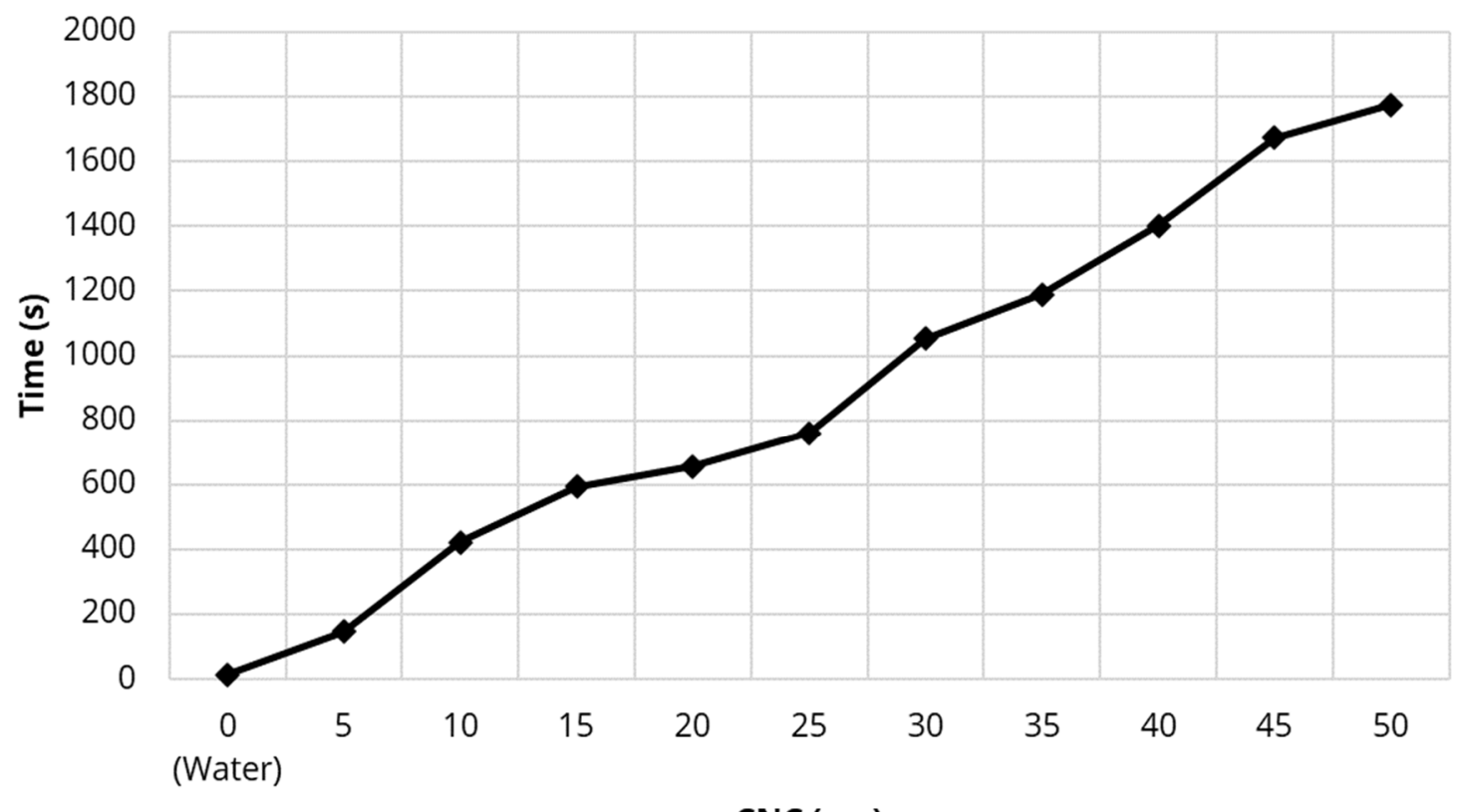

\section{CNC (mg)}

Figure 3. Effect of filtering increasing amounts of nanocrystalline cellulose (CNC) onto the Millipore small-scale filter on the time for the suspension to filter.

\subsection{Zeta Potential of Covalently Modified CNC}

Zeta potential measures the surface charge on solid surfaces and gives an indication of whether the charged drugs will bind to such surfaces. The zeta potential of unmodified $\mathrm{CNC}$ was $-50 \mathrm{mV}$ whereas covalent modification by cationic PDMC resulted in a positive charge across a range of $\mathrm{pH}$ as shown in Figure 5. The positive charge on the CNC was $\mathrm{pH}$ dependent and dropped with increased $\mathrm{pH}$. This $\mathrm{pH}$ dependency results from protonation of the covalently bound species at lower $\mathrm{pH}$ values further confirming an effective conjugation process. All surface charges remain strongly positive at all $\mathrm{pH}$ values and are likely to provide good binding sites for negatively charged drugs like diclofenac, especially in any reasonably anticipated water $\mathrm{pH}$ (perhaps 5 to 9 where the zeta potential only changes from approximately 60 to 40 ). The zeta potential of DDSA covalently modified $\mathrm{CNC}$ was reduced to $-20 \mathrm{mV}$ with the same value recorded at all $\mathrm{pH}$ values. 
(a)

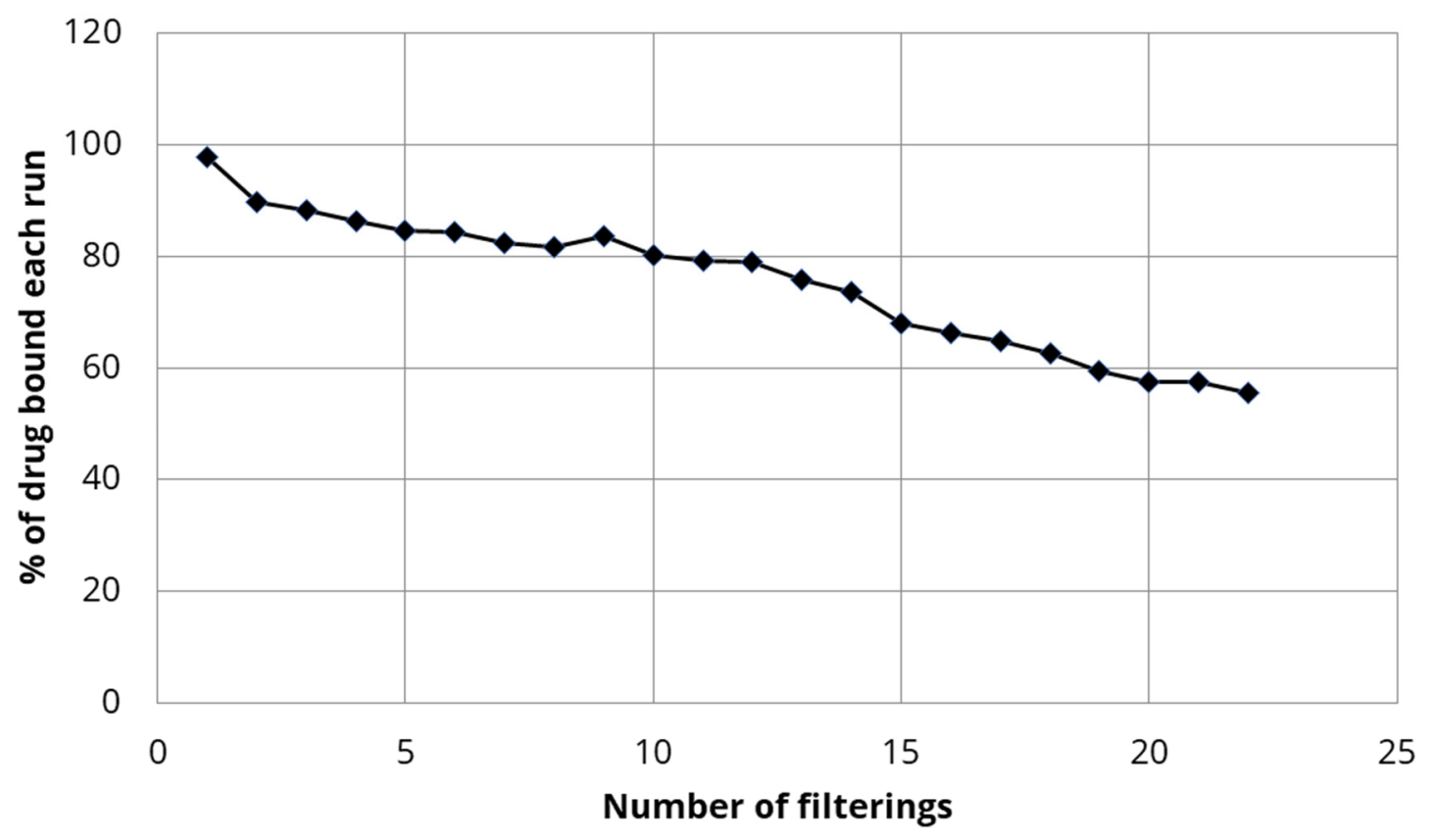

(b)

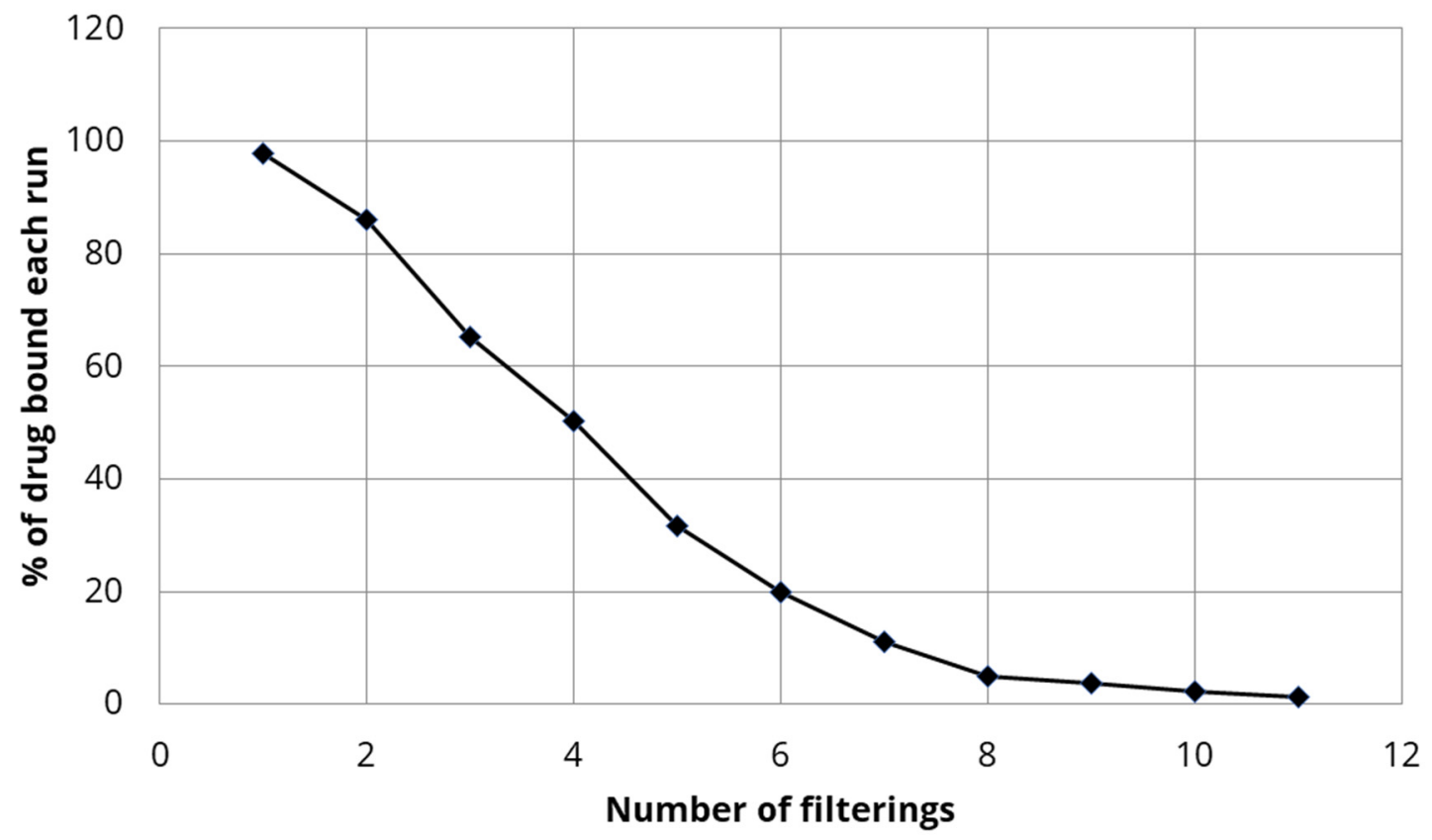

Figure 4. (a). Binding of estradiol (repeated $1 \mathrm{~mL}$ of $2 \mu \mathrm{g} / \mathrm{mL}$ ) to hydrophobic CNC (CTAB-CNC) (25 mg of CTAB-CNC integrated into small-scale filter). (b). Binding of estradiol (repeated $5 \mathrm{~mL}$ of $2 \mu \mathrm{g} / \mathrm{mL}$ ) to CTAB-CNC (5 mg of CTAB-CNC integrated into small-scale filter). 


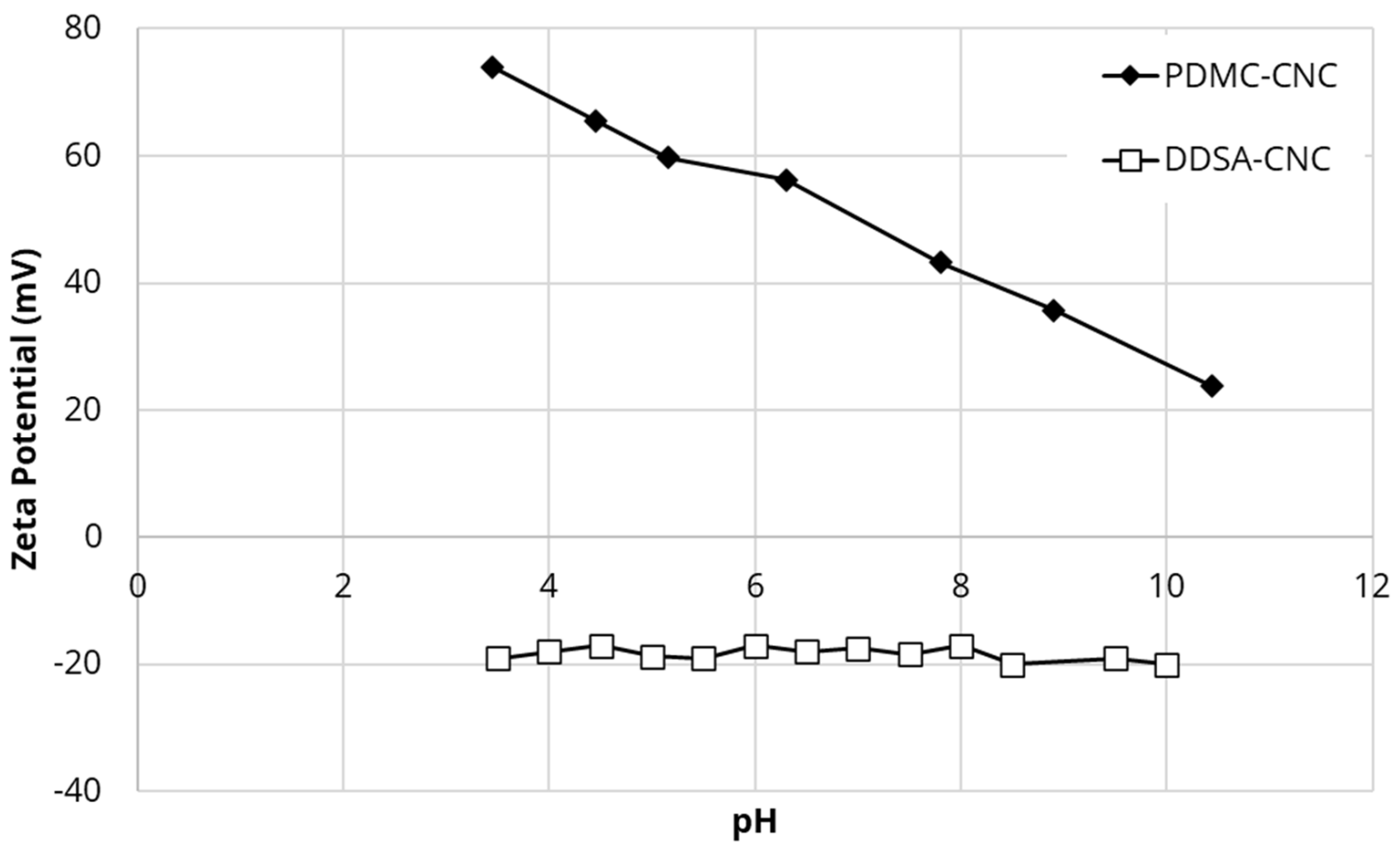

Figure 5. Zeta potential of covalently modified CNC as a function of $\mathrm{pH}$.

\subsection{Binding of Estradiol to DDSA-CNC Integrated Small Scale Membranes}

The \% binding of estradiol to either $5 \mathrm{mg}$ or $10 \mathrm{mg}$ DDSA-CNC loaded filters was found to be weak as seen in Figure 6a,b. Using $5 \mathrm{mg}$ of DDSA-CNC resulted in just 50\% of available drug being bound to the membrane and this binding dropped off quickly to almost zero by run 3. Similarly, the use of $10 \mathrm{mg}$ of DDSA-CNC on the small filter resulted in more drug being bound than for $5 \mathrm{mg}$ loaded membranes with over $70 \%$ available drug bound on the first run dropping to approximately $30 \%$ for runs 3 to 6 with a drop off to zero \% binding by run 9 .

\subsection{Binding of Estradiol to DDSA-CNC Integrated Large Commercial Filter Membranes}

When DDSA-CNC ( $2 \mathrm{~g})$ was integrated into a large commercial filter the binding of estradiol ( $2 \mathrm{~L}$ of solution at $2 \mu \mathrm{g} / \mathrm{mL}$ ) was significantly higher with $67 \%$ of available drug bound on the first run (Figure 7). However, although this dropped slightly after the first filtration run the binding stabilized at approximately 50\% levels for all subsequent runs (12 completed runs). The reason for the slightly lower values between run 2 and 5 is not known.

\subsection{Binding of Diclofenac to PDMC Integrated Small Scale Membranes}

The binding of diclofenac to either $5 \mathrm{mg}$ or $20 \mathrm{mg}$ PDMC-CNC loaded membranes was very high as seen in Figure 8a,b. For $5 \mathrm{mg}$ PDMC-CNC, initial binding levels were at $90 \%$ then stabilized slightly lower at between $70 \%$ and $90 \%$ for 40 repeated filtration runs (Figure 8a). Using $20 \mathrm{mg}$ PDMC-CNC, slightly higher levels of binding were observed and started at $90 \%$ binding on the first run dropping and stabilizing at between $80 \%$ and $90 \%$ after run 6 (12 runs completed) (Figure $8 b$ ). 
(a)

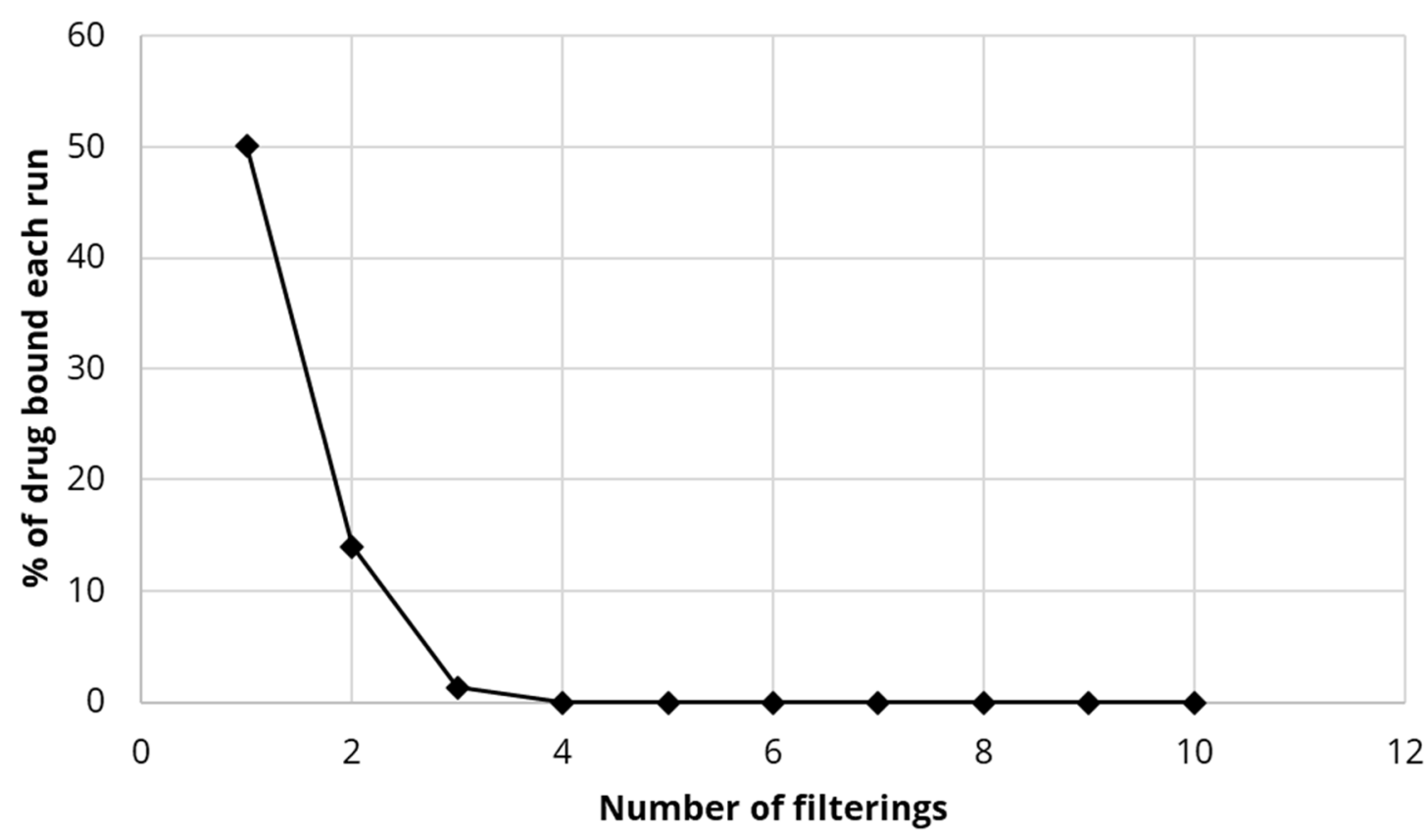

(b)

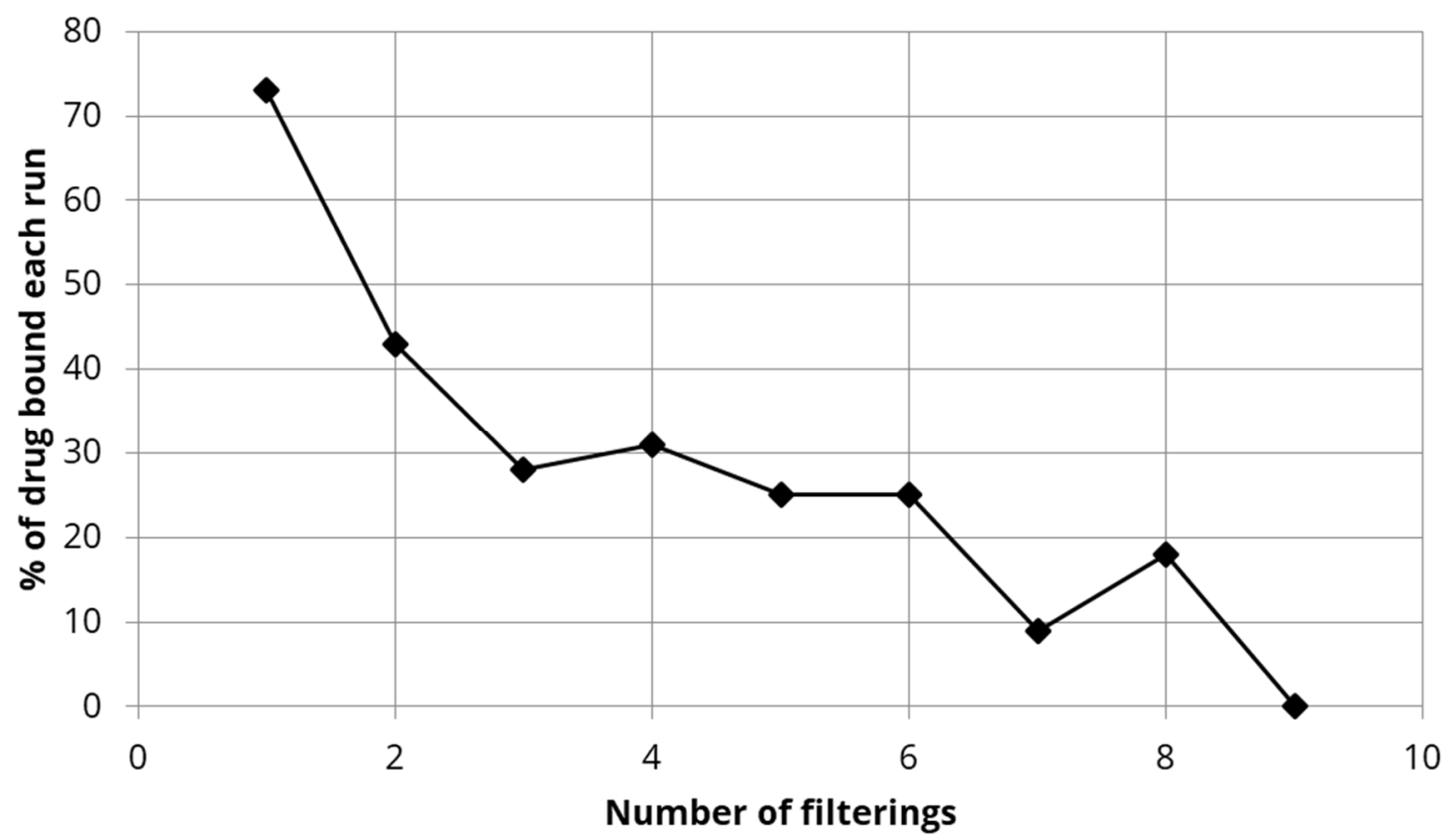

Figure 6. (a). Binding percentage of estradiol (repeated volumes of $5 \mathrm{~mL}$ of $2 \mu \mathrm{g} / \mathrm{mL}$ ) for DDSA-CNC ( $5 \mathrm{mg}$ integrated into the small-scale filter). (b). Binding percentage of estradiol (repeated volumes of $5 \mathrm{~mL}$ of $2 \mu \mathrm{g} / \mathrm{mL}$ ) for DDSA-CNC (10 mg integrated into the small-scale filter. 


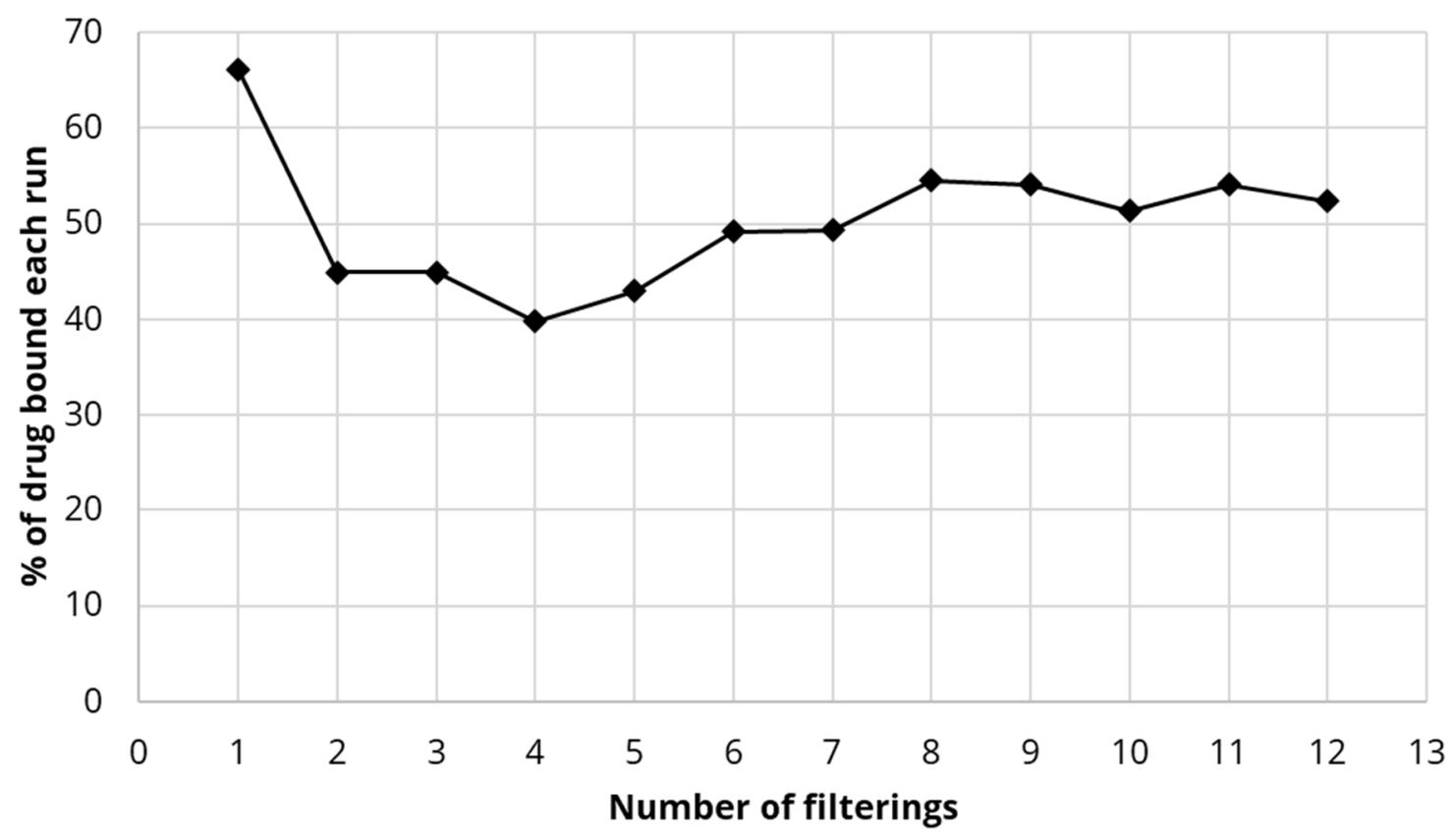

Figure 7. Binding percentage of estradiol (repeated volumes of $2 \mathrm{~L}$ of $2 \mu \mathrm{g} / \mathrm{mL}$ ) for DDSA-CNC (2 g) integrated into commercial filter.

(a)

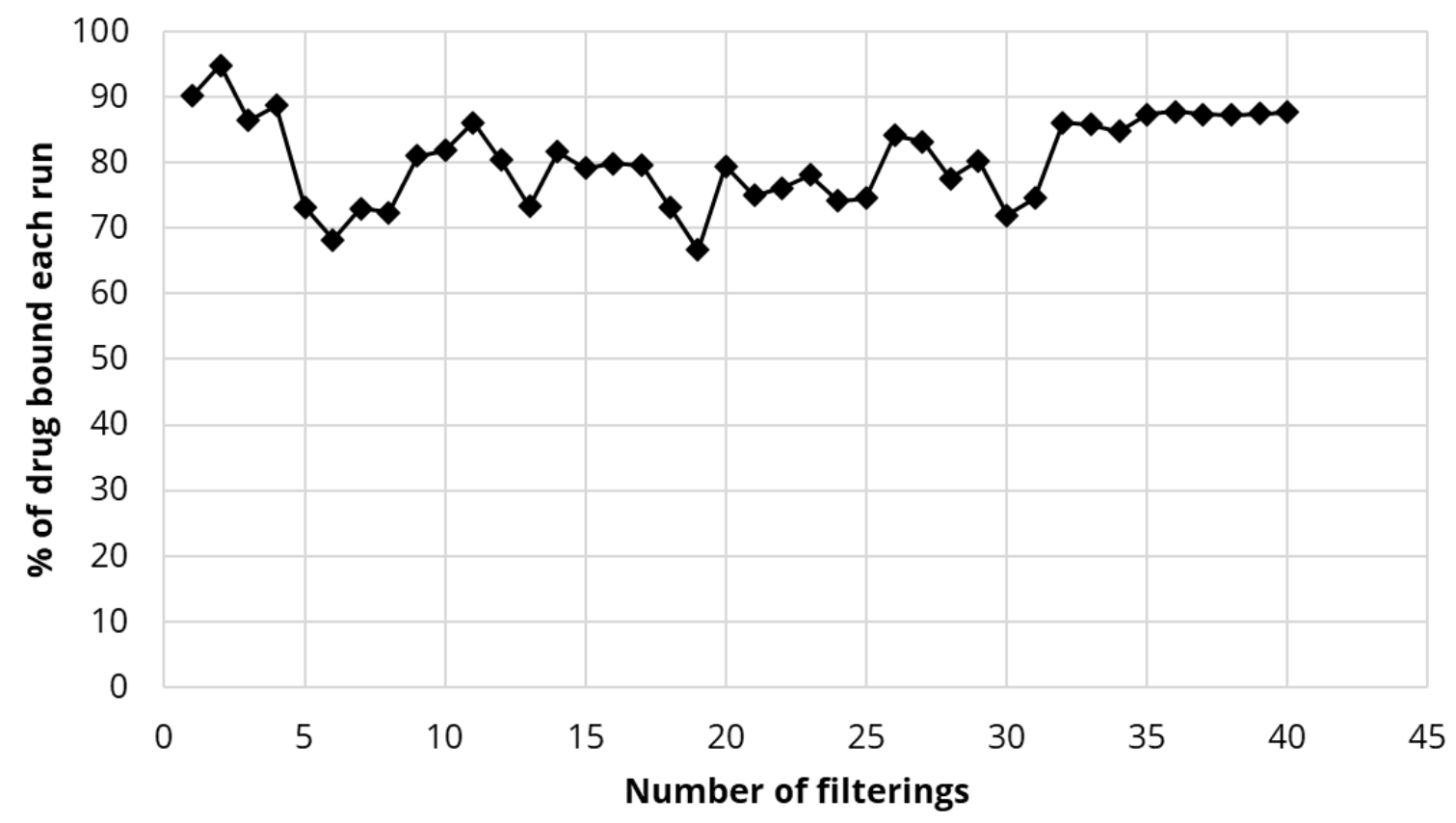

Figure 8. Cont. 
(b)

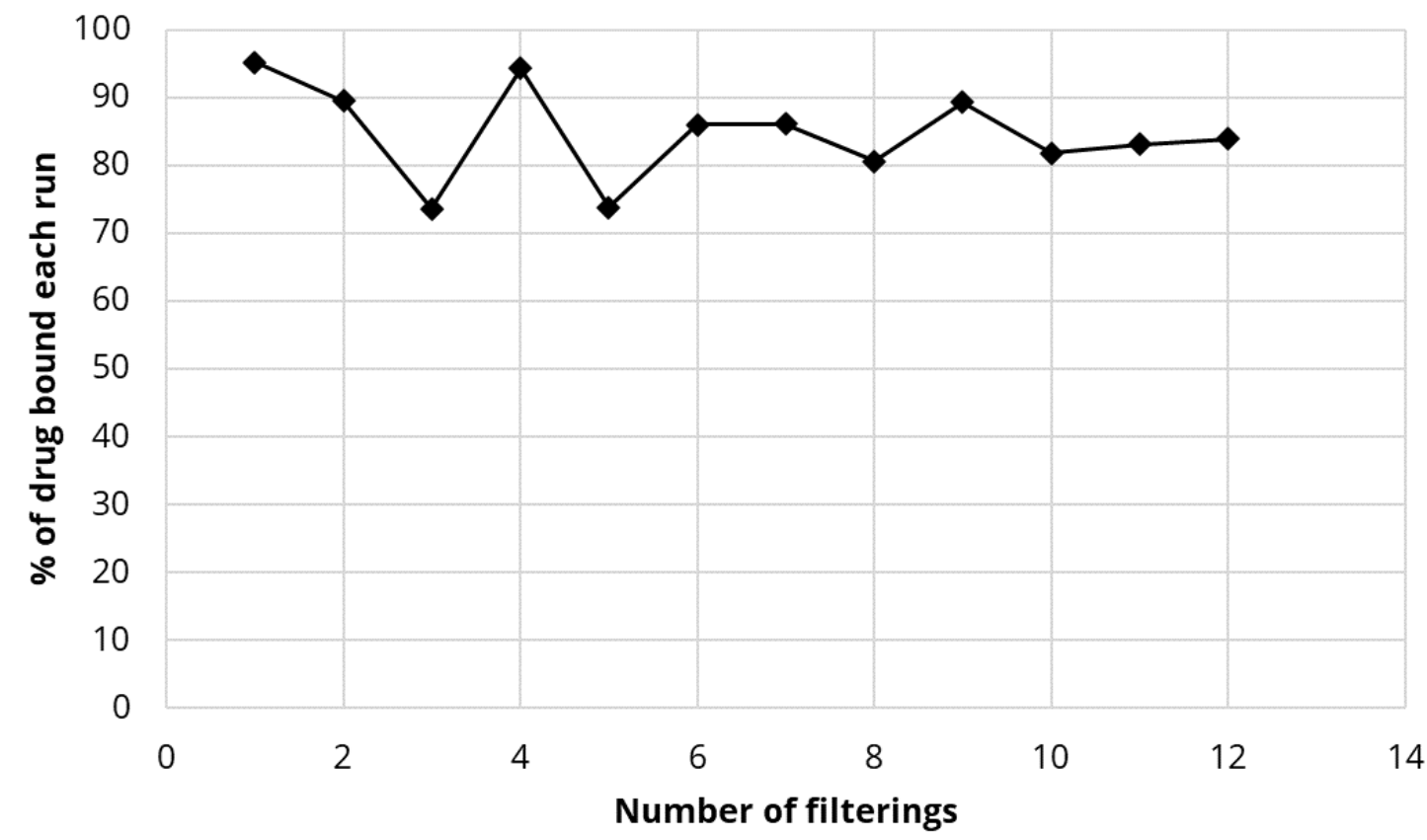

Figure 8. (a). Binding percentage of diclofenac (repeated volumes of $5 \mathrm{~mL}$ of $2 \mu \mathrm{g} / \mathrm{mL}$ ) for polydiallyl dimethyl ammonium chloride-CNC (PDMC-CNC) (5 mg integrated small-scale filter. (b). Binding percentage of diclofenac (repeated volumes of $5 \mathrm{~mL}$ of $2 \mu \mathrm{g} / \mathrm{mL})$ for PDMC-CNC (20 mg) integrated small-scale filter.

\subsection{Binding of Diclofenac to PDMC Integrated Large Commercial Filter Membranes}

The binding of diclofenac to large-scale membranes was lower at between $47 \%$ and $49 \%$ for six runs dropping and stabilizing at a level of approximately $40 \%$ after that (17 filtration runs completed) as seen in Figure 9.

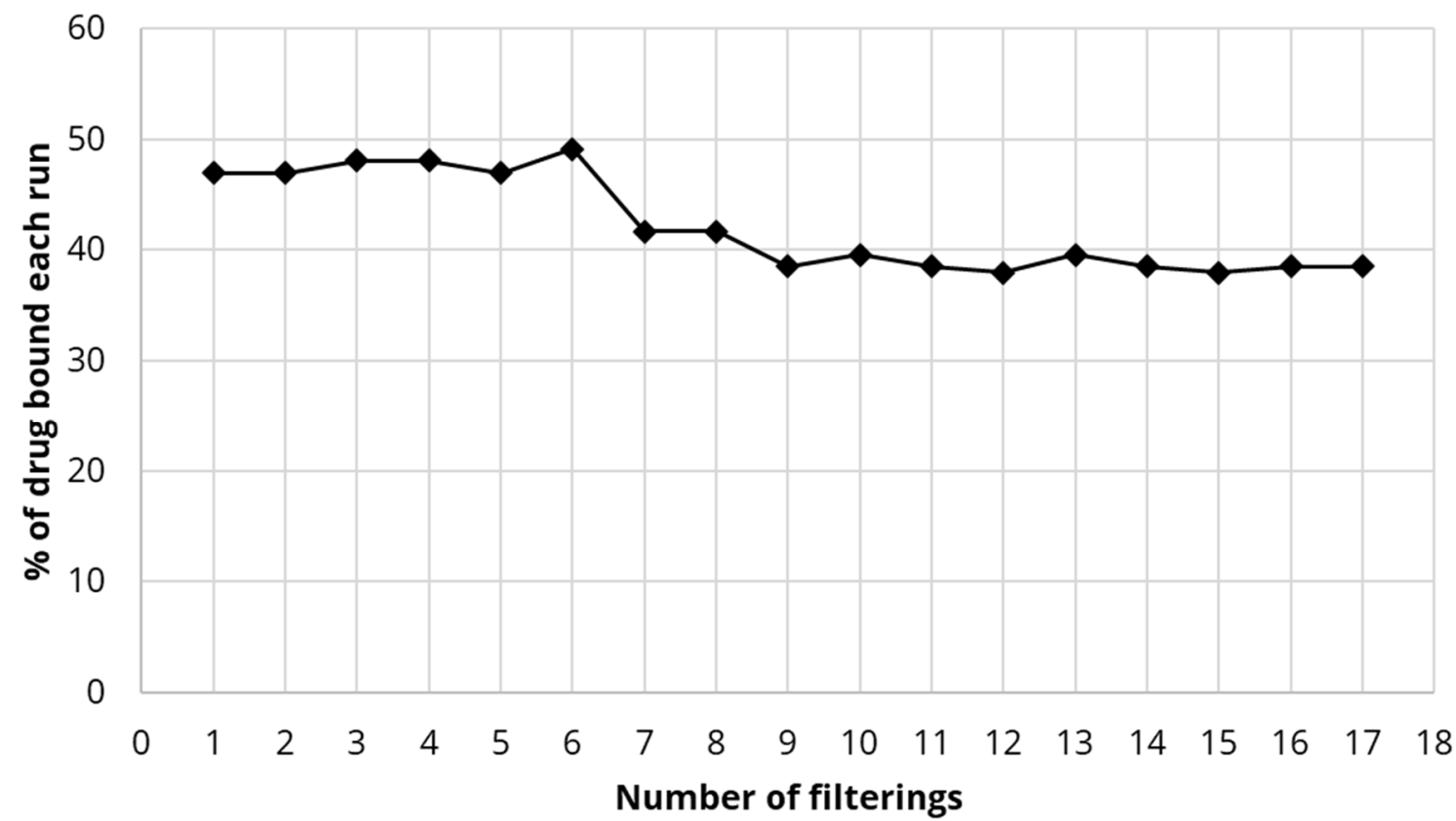

Figure 9. Binding percentage of diclofenac (repeated volumes of $2 \mathrm{~L}$ of $2 \mu \mathrm{g} / \mathrm{mL}$ ) for the PDMC-CNC (2 g) integrated commercial filter. 


\subsection{Oil Sands Treatments and Clay Flocculation}

Cloisite clay had a negative zeta potential of $-40 \mathrm{mV}$ as seen in Table 1 . The charge on unmodified CNC was also negative at $-50 \mathrm{mV}$. However, this dropped to $-20 \mathrm{mV}$ for $\mathrm{CTAB}$ modification and became highly positive for cationically modified CTAC-CNC $(+41 \mathrm{mV})$ (Table 1).

Table 1. Zeta potential of CNC and clay.

\begin{tabular}{cc}
\hline Sample Materials & Zeta Potential (mV) \\
\hline Cloisite clay & $-40 \mathrm{mV}$ \\
\hline Nanocrystalline cellulose (CNC) & $-50 \mathrm{mV}$ \\
\hline Cationic CNC (CTAC-CNC) & $+41 \mathrm{mV}$ \\
\hline CTAB-CNC (15 mM CTAB) & $-20 \mathrm{mV}$ \\
\hline
\end{tabular}

The addition of CTAC-CNC to Cloisite clay suspensions resulted in a concentration dependent binding and flocculation effect as seen in Figure 10. Flocculation levels were approximately $10 \%$ for each $\mathrm{mg}$ of CTAC-CNC added so that after $9 \mathrm{mg}$ almost $100 \%$ flocculation had occurred.

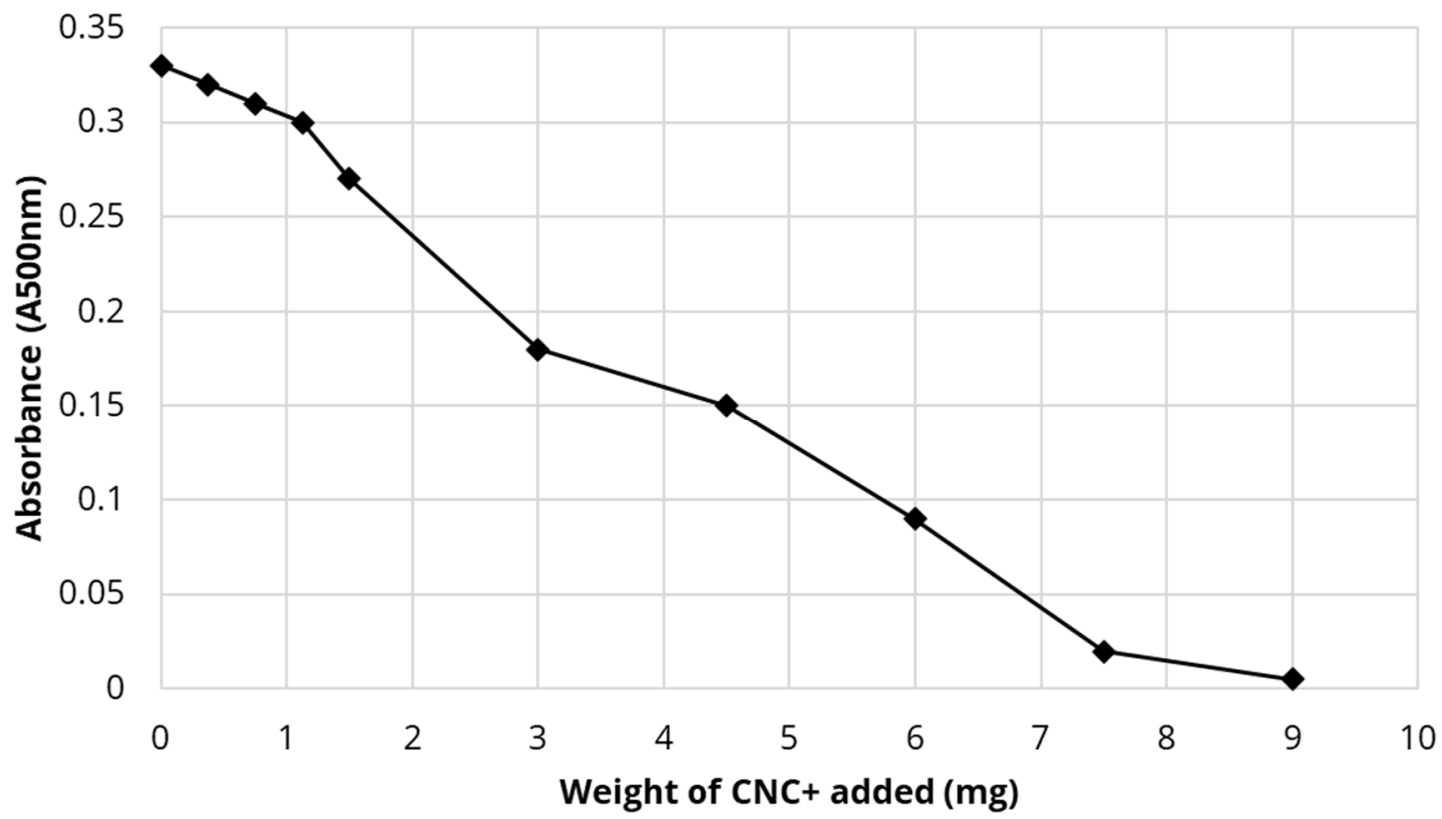

Figure 10. Flocculation of Cloisite clay $(20 \mathrm{mg})$ by CTAC-CNC. Turbidity absorbance at $500 \mathrm{~nm}$ after mild centrifugation.

\subsection{Binding of Naphthenic Acids to either CTAC-CNC or CTAB-Modified CNC}

The binding of both naphthenic acids to CTAC-CNC was weak as shown in Figure 11A. Binding levels of between $55 \%$ and $40 \%$ were observed over a range of butyl phenyl butanoic acid concentrations and approximately $30 \%$ binding levels for naphthyloxy butanoic acid (Figure 11A). The binding of both naphthenic acids to CTAB-CNC was strong across the full range of naphthenic acid concentrations (Figure 11B,C). Using CTAB modification of CNC at $15 \mathrm{mM}$ and CTAB-CNC at $15 \mathrm{mg} / \mathrm{mL}$, there was approximately $90 \%$ binding of naphthyloxy butanoic acid dropping to approximately $40 \%$ using CTAB (7.5 mM modified) bound to CNC at $7.5 \mathrm{mg} / \mathrm{mL}$ and slightly higher at between $40 \%$ to $60 \%$ for CTAB $(7.5 \mathrm{mM}$ modified) bound to CNC at $15 \mathrm{mg} / \mathrm{mL}$ (Figure 11B). These values were unaffected by naphthenic acid concentration. 
(A)

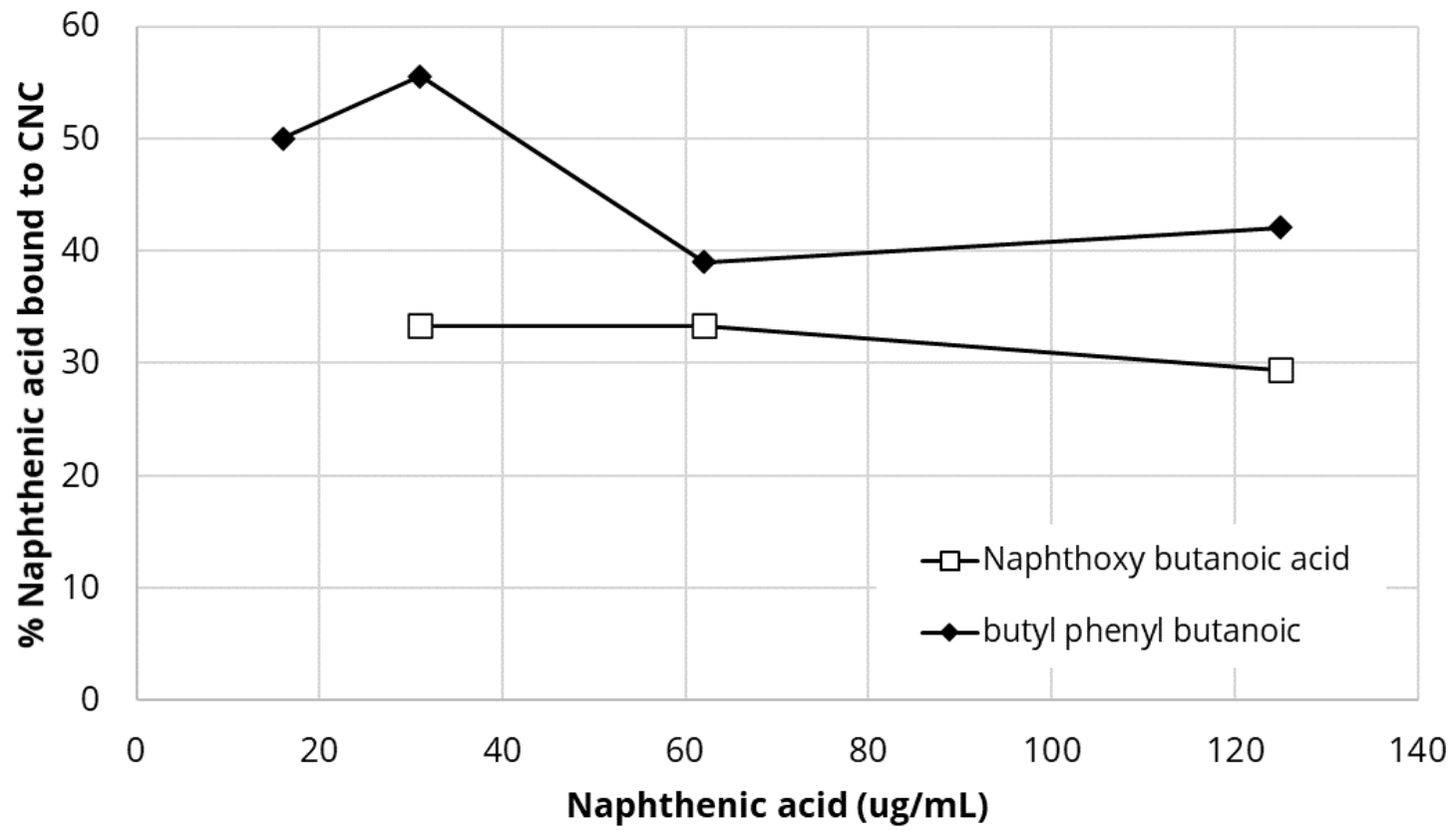

(B)

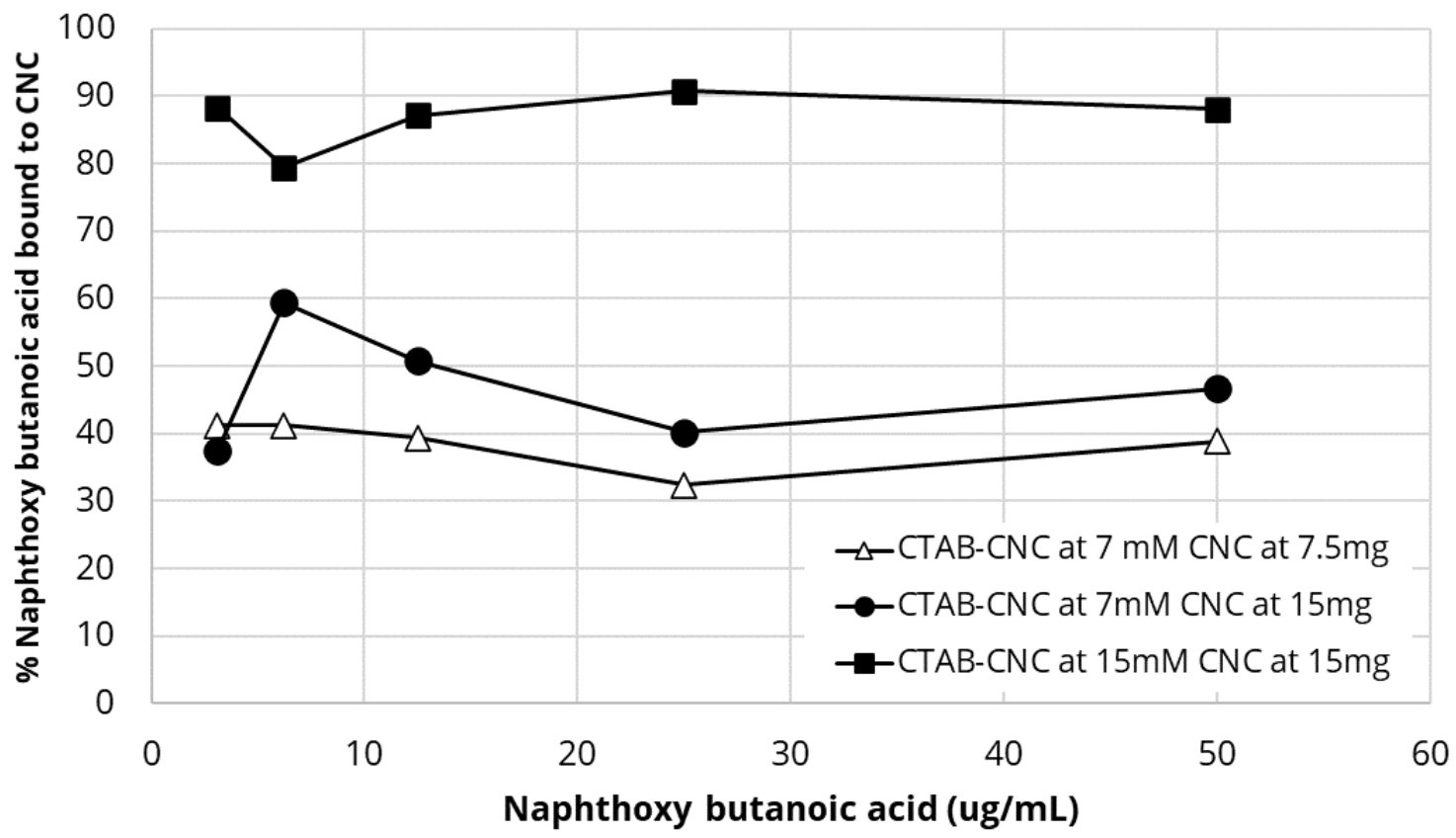

Figure 11. Cont. 
(C)

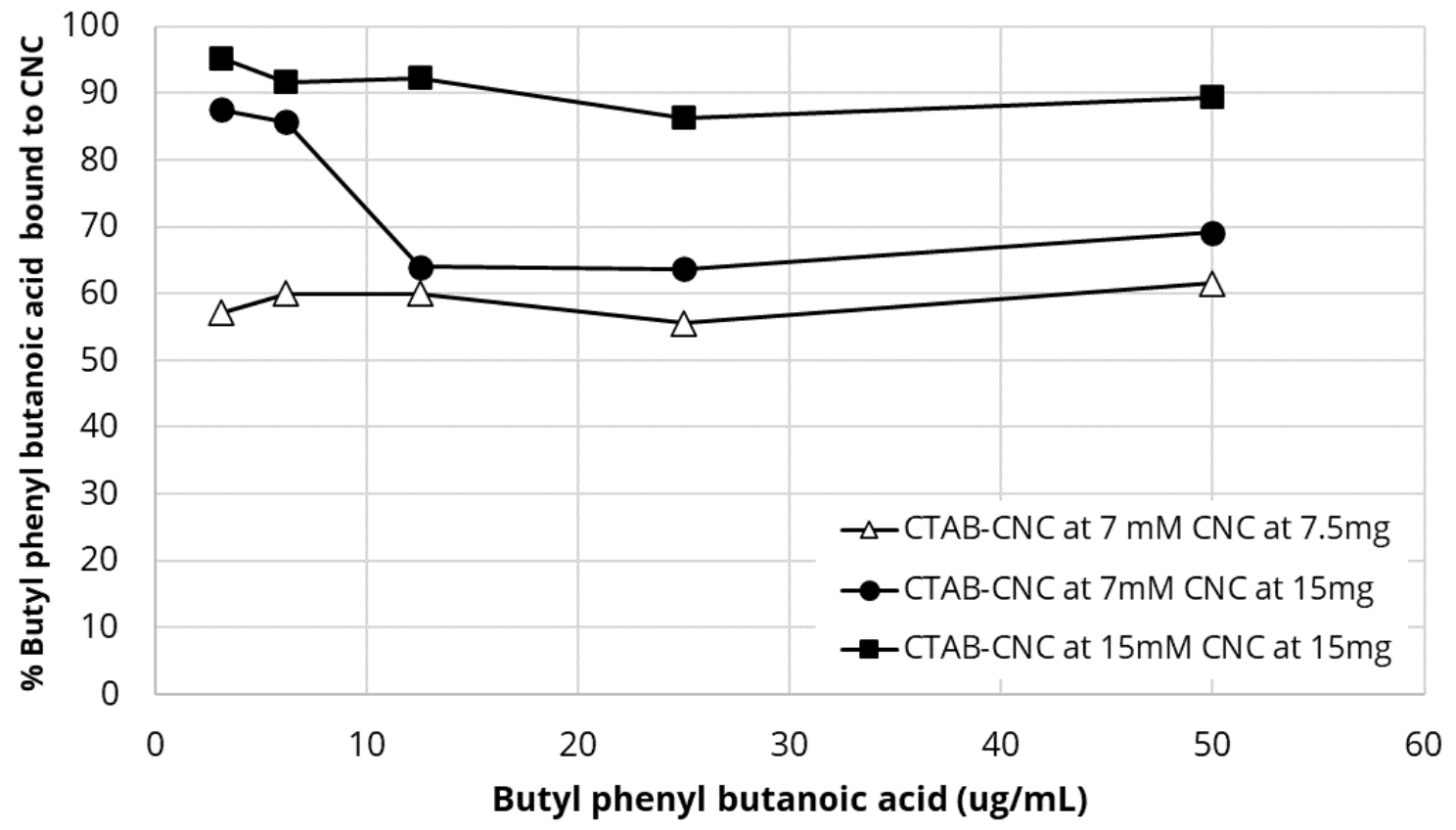

Figure 11. (A) Binding of butanoic acids to cationic CNC. CTAC-CNC. (B) Binding of naphthoxy butanoic acid to CTAB-CNC. (C) Binding of butyl phenyl butanoic acid to CTAB-CNC.

The binding of butyl phenyl butanoic acid to CTAB-CNC (Figure 11C) followed a similar pattern to naphthyloxy butanoic acid binding data except with values slightly higher. Using CTAB modification of CNC at $15 \mathrm{mM}$ and CTAB-CNC at $15 \mathrm{mg} / \mathrm{mL}$ there was approximately $90 \%$ binding, dropping to approximately $60 \%$ using CTAB $(7.5 \mathrm{mM}$ modified) bound to CNC at $7.5 \mathrm{mg} / \mathrm{mL}$, and slightly higher at between $65 \%$ to $90 \%$ for CTAB (7.5 mM modified) bound to CNC at $15 \mathrm{mg} / \mathrm{mL}$ (Figure 11C). These values were unaffected by naphthenic acid concentration.

\section{Discussion}

In this study, the potential use of surface-modified CNC to remove estradiol or diclofenac from water and the ability of modified CNC to reduce the two major environmental polluting aspects of the oil sands industry, namely the persistent clay and naphthenic acid content of tailings ponds, was investigated. Nanocrystalline cellulose is a readily available, ecologically suitable material for remediation purposes and it has the added advantage of being easily surface derivatized to create surfaces for specific adsorbing purposes [36-38]. Nanocrystalline cellulose, either native or surface modified, has been proposed for use in removing metal, oil and pharmaceutical contaminants from water [38].

Initially, $\mathrm{CNC}$ was found to partially pass though large pore size $(1 \mu \mathrm{m})$ filters but was reproducibly and fully trapped on $0.2 \mu \mathrm{m}$ filters without blocking water passage (Figure 3 ) establishing the concept of a simple one-step procedure for modifying existing commercial filters for the purpose of drug removal. In this study, known methods to surface modify $\mathrm{CNC}$ into hydrophobic surfaces in an attempt to bind estradiol or naphthenic acids were used. Similarly, cationic surfaces were provided to bind negatively charged diclofenac or naphthenic acids. These methods included simple chemical species binding to $\mathrm{CNC}$ or more complex covalent modification methods. The zeta potential of native $\mathrm{CNC}$ was found to be negative at $-50 \mathrm{mV}$ (Table 1) as previously reported [12]. It has been previously shown that the hydrophobic modifying group CTAB bound well to CNC as reported by a less negative zeta potential [12] and this was confirmed in this study. A similar change in the zeta potential of CNC covalently modified with the hydrophobic DDSA group was also found and this zeta potential was found to be $-20 \mathrm{mV}$ over a wide range of $\mathrm{pHs}$ 
(Figure 5). The efficient adsorption of cationic CTAC to CNC was confirmed by the positive zeta potential of $+41 \mathrm{mV}$ (Table 1). Similarly, the effective covalent cationization of CNC by PDMC was also confirmed by a positive zeta potential over a wide range of $\mathrm{pH}$ with the reduction of positive zeta potential at higher $\mathrm{pH}$ (Figure 5) reflecting the mild acidic nature of the cationic ammonium ion.

The two important aspects of removing discarded drugs from water are removal from waste water treatment plants (WWTP) at the effluent stage and removal from drinking water. Concentrations of drugs in the effluent of WWTP and discarded into rivers may contain higher drug concentrations [39] $(<100 \mathrm{ng} / \mathrm{L})$ and present significant unwanted toxicity to aquatic life. On the other hand, concentrations in drinking water accessed from polluted rivers may be lower $(<50 \mathrm{ng} / \mathrm{L})$ [39] due to city drinking water treatment plants. However, in dry areas of the world, water may be recycled many times so that drug removal is particularly important in these regions. Removal of drugs at WWTP is generally quite effective and occurs in the activated sludge phase of treatment $[14,15,39]$. However, two drugs in particular, estradiol and diclofenac, are heavily used and discarded into the sewerage systems and are poorly degraded in the activated sludge [14-17] and have been added to the European list of drugs of environmental concern [40]. Whilst effluent treatment using ozonation, activated carbon or ultrafiltration (reverse osmosis) are quite effective in removing these drugs [41-44], these methods are unlikely to be adopted due to the high cost of retrofitting and operation (power) of the WWTP [40]. Furthermore, ultrafiltration or activated carbon treatment methods also have problems with fouling, short lifetimes and environmental disposal [42,44-46].

The drug estradiol bound strongly to $0.2 \mu \mathrm{m}$ filter membranes containing integrated hydrophobically modified CNC. Using higher loadings of CTAB-modified CNC, almost $100 \%$ binding of estradiol was achieved on small scale filters (Figure 4a) whereas the drug bound less strongly to covalently modified DDSA-CNC (approx. 70-50\%) (Figure 6a,b). Using a commercial over-the-counter household filtration system the DDSA-CNC integrated cartridge $(0.2 \mu \mathrm{m})$ adsorbed approximately $70 \%$ of the estradiol on the first run but maintained a $50 \%$ extraction level after that for multiple runs (Figure 7). Although these data do not show a consistent full capture of the drug, they do show the excellent potential of $\mathrm{CNC}$ based systems like this to clear estradiol from water. It is unlikely that non-covalently modified CTAB-CNC would be used in household cartridges before a tap outlet as there would be a perceived risk of $\mathrm{CTAB}$ eluting into the drinking water. However, in waste water treatment minor amounts of CTAB eluting from membranes would not be problematic due to dilution and because a similar ammonium product [47] is already used in many water treatment systems for pollutant removal.

The charged drug diclofenac was found to bind well to PDMC-CNC integrated membranes both in a small-scale system (approx. 90\% binding) or the commercial household filter (a robust $40-50 \%$ binding) but, similar to estradiol, it was not possible to achieve $100 \%$ efficiencies (Figures 8 and 9). The increased use (and sewage disposal) globally of diclofenac and the poor breakdown by the activated sludge of WWTP has heightened environmental concerns about this drug $[1,39,48]$. These initial data clearly demonstrate the ability of cationically modified $\mathrm{CNC}$ to remove charged species like diclofenac.

In a review of cellulosic material use in waste water treatment technologies, Carpenter et al. [38], pointed out that CNC may provide a support for other active adsorbing particles or may be sorbed onto an existing membrane structure. Furthermore, CNC is easily carboxylated or modified for subsequent covalent modification and hydrophobically trapped species can often be removed by solvent washing with preferable sustainable consequences. All of these features of CNC for waste water treatment have been reinforced in these studies. It should be remembered that nearly all advanced drug elimination procedures like activated carbon traps or ozonation do not fully remove drugs from water [42-44]. Drug trapping by ultrafiltration is more efficient but does not achieve 100\% removal efficiency and membrane fouling is a persistent problem [42,45,46]. Yangali-Quintanilla et al. [45] showed that a $300 \mathrm{kPA}$ pressure ultrafiltration system allowed for approximately $90 \%$ of 
estradiol to be removed but fouling strongly affects removal efficiencies for numerous drugs. Carbon trapping is also associated with fouling problems [41,42] requiring repeated expensive replacement. Clearly these high-cost, advanced systems are unlikely to be used in most budget-conscious countries. The simplicity and sustainable nature of the use of modified CNC provided in these studies may offer an additional tool for removing drugs from waste water and particularly from drinking water where existing cartridge filters may be easily modified and fouling by other contaminants is less likely than in waste water.

Non-covalently modified cationic CTAC-CNC provided a powerful flocculating agent for clay as shown in Figure 10. Clays are tiny disc-shaped solids with particularly complex charged species often with arrays of both positive and negative charges on the outer rim surface of the disc and a negative charge on the disc faces. The negative charge on clays often increases with higher $\mathrm{pH}$ so that at $\mathrm{pH} \mathrm{8}$, as in the oil sands ponds, this use of cationic flocculating species is an attractive strategy [19]. However, numerous amphoteric or zwitterionic cellulosic polymers have been studied with moderate success as flocculating agents [49]. These agents may allow flocculation by bridging or charge neutralization (easiest) processes. In the review paper by Koshani et al. [49], the simplest and most commonly used flocculating method has been to use cationic quaternary ammonium surface modification of many types of cellulose, microcellulose and nanocellulose. Cationically modified cellulose in macro form has been shown to flocculate numerous pollutants including clays (Table 2 in [49]). Quaternary ammonium cationic modification of hairy nanofibers of cellulose (HNC) or cellulose nanofibers results in good flocculants for clays often in the presence of calcium species (Table 3 in [49]). The excellent flocculation of clay observed by Campano et al. [50] was achieved by using hairy cellulose nanofibers where only the end groups on the chains were cationially charged, allowing the long chains to bind to the clay disc faces and bridge and neutralize the negative surface charge. In a similar manner, it is proposed that that the strong positive charge of the CTAC-modified CNC may interact directly with the negative surface charge of the clay causing the observed flocculation.

Naphthenic acids present as pollutants in oil sand tailings ponds are a series of aliphatic and alicyclic carboxylic acids with a pKa in the 5-6 range so at the $\mathrm{pH}$ of oil sands (approximately 8 ) these compounds are generally negatively charged but also vary significantly in their degree of hydrophobicity $[25,27,29]$. In these studies, we used a more aromatic naphthyloxy butanoic acid and a more complex mixed aliphatic/aromatic compound often used in oil sands naphthenic acid toxicity studies, butyl phenyl butanoic acid [51,52]. Naphthenic acids pollutants are present in oil sands tailings ponds at up to $120 \mu \mathrm{g} / \mathrm{mL}$ concentrations $[53,54]$ and so in these binding studies the naphthenic acids were used at similar concentrations. Both naphthyloxy butanoic acid and butyl phenyl butanoic acid bound strongly (approximately $90 \%$ ) to the hydrophobically modified CTAB-CNC, as shown in Figure 11. There was a lower level of binding (approx. 40\%) to positively charged CTAC-CNC. There are few reports of cellulose based products to clean up naphthenic acid extracts but Frank et al. [28] used a weak anion exchanger with DEAE-modified cellulose which allowed for approximately $41 \%$ efficiency of extraction.

Other workers report the use of flocculation to bind and separate naphthenic acids using the positively charged PDMC (poly(diallyldimethylammonium chloride) (PDMC is the same as the covalently cationic species used in the water purification part of this study) with 37\% efficiencies (reviewed in [27]). More recently ozonation of naphthenic acids has been shown to produce oxidized naphthenic species which are more readily biodegraded $[27,55]$ and interestingly may be flocculated using PDMC at higher efficiencies $(86 \%)$ than observed for native compounds. Ultrafitration methods are quite effective in the laboratory for removing naphthenic acids from water but in the real world rapid fouling of the membranes makes this method unviable [27]. Future studies in this laboratory will focus on synergistic extraction methods whereby CNC-CTAC flocculated clays may coflocculate bound CNC-CTAC or CTAB-CNC naphthenic acid complexes. It is likely that generally lower efficiency water purification steps may be used in combination or in sequence to achieve satisfactory naphthenic acid removal [55]. The inclusion of such 
steps will strongly depend on budgetary considerations and environmental compatibility such as clean up, disposal or biodegradation. Clearly, nanocrystalline cellulose fits both budgetary and environmental requirements.

\section{Conclusions}

In this study, it has been shown that CNC may be easily surface modified to produce positively charged or hydrophobic surfaces. These modified nanofibres may be integrated into existing $0.2 \mu \mathrm{m}$ commercial filters using low-pressure filtration and may adsorb either negatively charged drugs like diclofenac or hydrophobic drugs like estradiol. Furthermore, the adsorption of cationic or hydrophobic chemicals onto the surface of CNC provides materials that may be simply mixed with clay suspensions or naphthenic acid solutions to either flocculate clays or bind naphthenic acids. Similar to almost all remediation systems for cleaning water, these CNC-based systems are not $100 \%$ effective but may offer a complementary method to other clean-up procedures for a cumulative cleaning effect.

Author Contributions: Conceptualization, J.J. and D.P.; methodology, A.M. and M.C.; investigation, A.M. and J.J. and D.P.; writing-original draft preparation, J.J.; writing-review and editing, J.J. and M.C. and D.P.; supervision, M.C.; project administration, D.P. All authors have read and agreed to the published version of the manuscript.

Funding: The Alberta Innovates CNC Challenge 2.0 Program.

Institutional Review Board Statement: Not applicable.

Informed Consent Statement: Not applicable.

Data Availability Statement: Not applicable.

Conflicts of Interest: The authors declare no conflict of interest.

\section{References}

1. World Health Organization. Pharmaceuticals in Drinking-Water; WHO: Geneva, Switzerland, 2012; ISBN 978-92-4-150208-5.

2. World Health Organization. Pharmaceuticals in Drinking-Water (WHO/HSE/WSH/11.05); WHO: Geneva, Switzerland, 2011.

3. Rivera-Utrilla, J.; Sánchez-Polo, M.; Ferro-García, M.Á.; Prados-Joya, G.; Ocampo-Pérez, R. Pharmaceuticals as emerging contaminants and their removal from water. A review. Chemosphere 2013, 93, 1268-1287. [CrossRef]

4. Chauhan, A.; Sillu, D.; Agnihotri, S. Removal of pharmaceutical contaminants in wastewater using nanomaterials: A comprehensive review. Curr. Drug Drug Metab. 2019, 20, 483-505. [CrossRef]

5. Karn, B.; Kuiken, T.; Otto, M. Nanotechnology and in situ remediation: A review of the benefits and potential risks. Environ. Health Perspect. 2009, 117, 1813-1831. [CrossRef]

6. Wei, H.; Rodriguez, K.; Renneckar, S.; Vikesland, P.J. Environmental science and engineering applications of nanocellulose-based nanocomposites. Environ. Sci. Nano 2014, 1, 302-316. [CrossRef]

7. Habibi, Y.; Lucia, L.A.; Rojas, O.J. Cellulose nanocrystals: Chemistry, self-assembly, and applications. Chem. Rev. 2010, 110, 3479-3500. [CrossRef] [PubMed]

8. Liu, Y.; Liu, H.; Shen, Z. Nanocellulose Based Filtration Membrane in Industrial Waste Water Treatment: A Review. Materials 2021, 14, 5398. [CrossRef] [PubMed]

9. Voisin, H.; Bergström, L.; Liu, P.; Mathew, A.P. Nanocellulose-based materials for water purification. Nanomaterials 2017, 7, 57. [CrossRef] [PubMed]

10. Sharma, P.R.; Sharma, S.K.; Lindström, T.; Hsiao, B.S. Nanocellulose-Enabled Membranes for Water Purification: Perspectives. Adv. Sustain. Syst. 2020, 4, 1900114. [CrossRef]

11. Mahfoudhi, N.; Boufi, S. Nanocellulose as a novel nanostructured adsorbent for environmental remediation: A review. Cellulose 2017, 24, 1171-1197. [CrossRef]

12. Jackson, J.K.; Letchford, K.; Wasserman, B.Z.; Ye, L.; Hamad, W.Y.; Burt, H.M. The use of nanocrystalline cellulose for the binding and controlled release of drugs. Int. J. Nanomed. 2011, 6, 321.

13. Karimian, A.; Parsian, H.; Majidinia, M.; Rahimi, M.; Mir, S.M.; Kafil, H.S.; Shafiei-Irannejad, V.; Kheyrollah, M.; Ostadi, H.; Yousefi, B. Nanocrystalline cellulose: Preparation, physicochemical properties, and applications in drug delivery systems. Int. J. Biol. Macromol. 2019, 133, 850-859. [CrossRef] [PubMed]

14. Nas, B.; Dolu, T.; Argun, M.E.; Yel, E.; Ateş, H.; Koyuncu, S. Comparison of advanced biological treatment and nature-based solutions for the treatment of pharmaceutically active compounds (PhACs): A comprehensive study for wastewater and sewage sludge. Sci. Total Environ. 2021, 779, 146344. [CrossRef] 
15. Vieno, N.; Sillanpää, M. Fate of diclofenac in municipal wastewater treatment plant-A review. Environ. Int. 2014, 69, 28-39. [CrossRef] [PubMed]

16. Barbosa, M.O.; Moreira, N.F.; Ribeiro, A.R.; Pereira, M.F.; Silva, A.M. Occurrence and removal of organic micropollutants: An overview of the watch list of EU Decision 2015/495. Water Res. 2016, 94, 257-279. [CrossRef]

17. Nguyen, P.; Carvalho, G.; Reis, M.A.; Oehmen, A. A review of the biotransformations of priority pharmaceuticals in biological wastewater treatment processes. Water Res. 2020, 188, 116446. [CrossRef] [PubMed]

18. Fair, A. Oil Sands tailings: A historical perspective. In Proceedings of the Fourth International Oil Sands Tailings Conference (IOSTC), Lake Louis, AB, Canada, 7-10 December 2014.

19. Botha, L.; Soares, J.B. The influence of tailings composition on flocculation. Can. J. Chem. Eng. 2015, 93, 1514-1523. [CrossRef]

20. Vedoy, D.R.; Soares, J.B. Water-soluble polymers for oil sands tailing treatment: A Review. Can. J. Chem. Eng. 2015, 93, 888-904. [CrossRef]

21. Wang, X.; Feng, X.; Xu, Z.; Masliyah, J.H. Polymer aids for settling and filtration of oil sands tailings. Can. J. Chem. Eng. 2010, 88, 403-410. [CrossRef]

22. Sworska, A.; Laskowski, J.; Cymerman, G. Flocculation of the Syncrude fine tailings: Part I. Effect of pH, polymer dosage and $\mathrm{Mg}^{2+}$ and $\mathrm{Ca}^{2+}$ cations. Int. J. Miner. Process. 2000, 60, 143-152. [CrossRef]

23. Yang, X.; Zhang, L.; Jin, X.; Liu, L.; Zhang, Y.; Ni, Q.; Yao, J. Synthesis of hydrophobically modified cellulose-based flocculant and its application in treatments of kaolin suspension and machining wastewater. Cellulose 2017, 24, 5639-5647. [CrossRef]

24. Jin, L.; Wei, Y.; Xu, Q.; Yao, W.; Cheng, Z. Cellulose nanofibers prepared from TEMPO-oxidation of kraft pulp and its flocculation effect on kaolin clay. J. Appl. Polym. Sci. 2014, 131, 40450. [CrossRef]

25. Quagraine, E.; Peterson, H.; Headley, J. In situ bioremediation of naphthenic acids contaminated tailing pond waters in the Athabasca oil sands region-Demonstrated field studies and plausible options: A review. J. Environ. Sci. Health 2005, 40, 685-722. [CrossRef]

26. Scott, A.C.; Mackinnon, M.D.; Fedorak, P.M. Naphthenic acids in Athabasca oil sands tailings waters are less biodegradable than commercial naphthenic acids. Environ. Sci. Technol. 2005, 39, 8388-8394. [CrossRef]

27. Quinlan, P.J.; Tam, K.C. Water treatment technologies for the remediation of naphthenic acids in oil sands process-affected water. Chem. Eng. J. 2015, 279, 696-714. [CrossRef]

28. Frank, R.A.; Kavanagh, R.; Burnison, B.K.; Headley, J.V.; Peru, K.M.; Van Der Kraak, G.; Solomon, K.R. Diethylaminoethylcellulose clean-up of a large volume naphthenic acid extract. Chemosphere 2006, 64, 1346-1352. [CrossRef]

29. Mohamed, M.H.; Wilson, L.D.; Headley, J.V.; Peru, K.M. Novel materials for environmental remediation of tailing pond waters containing naphthenic acids. Process. Saf. Environ. Prot. 2008, 86, 237-243. [CrossRef]

30. Wu, C.; De Visscher, A.; Gates, I.D. On naphthenic acids removal from crude oil and oil sands process-affected water. Fuel 2019, 253, 1229-1246. [CrossRef]

31. Marentette, J.R.; Frank, R.A.; Bartlett, A.J.; Gillis, P.L.; Hewitt, L.M.; Peru, K.M.; Headley, J.V.; Brunswick, P.; Shang, D.; Parrott, J.L. Toxicity of naphthenic acid fraction components extracted from fresh and aged oil sands process-affected waters, and commercial naphthenic acid mixtures, to fathead minnow (Pimephales promelas) embryos. Aquat. Toxicol. 2015, 164, 108-117. [CrossRef]

32. Toor, N.S.; Franz, E.D.; Fedorak, P.M.; MacKinnon, M.D.; Liber, K. Degradation and aquatic toxicity of naphthenic acids in oil sands process-affected waters using simulated wetlands. Chemosphere 2013, 90, 449-458. [CrossRef] [PubMed]

33. Leszczyńska, A.; Radzik, P.; Szefer, E.; Mičušík, M.; Omastová, M.; Pielichowski, K. Surface modification of cellulose nanocrystals with succinic anhydride. Polymers 2019, 11, 866. [CrossRef] [PubMed]

34. Huang, P.; Wang, C.; Huang, Y.; Wu, M. Surface Modification of Nanocellulose. In Nanocellulose: Synthesis, Structure, Properties and Applications; World Scientific: Hadensack, NJ, USA, 2021; pp. 65-92.

35. Russell, J.A.; Malcolm, R.K.; Campbell, K.; Woolfson, A.D. High-performance liquid chromatographic determination of 17 $\beta$ estradiol and $17 \beta$-estradiol-3-acetate solubilities and diffusion coefficients in silicone elastomeric intravaginal rings. J. Chromatogr. B Biomed. Sci. Appl. 2000, 744, 157-163. [CrossRef]

36. Wang, D. A critical review of cellulose-based nanomaterials for water purification in industrial processes. Cellulose 2019, 26, 687-701. [CrossRef]

37. Heydarifard, S.; Nazhad, M.M.; Xiao, H.; Shipin, O.; Olson, J. Water-resistant cellulosic filter for aerosol entrapment and water purification, Part I: Production of water-resistant cellulosic filter. Environ. Technol. 2016, 37, 1716-1722. [CrossRef] [PubMed]

38. Carpenter, A.W.; de Lannoy, C.-F.; Wiesner, M.R. Cellulose nanomaterials in water treatment technologies. Environ. Sci. Technol. 2015, 49, 5277-5287. [CrossRef]

39. Comber, S.; Gardner, M.; Sörme, P.; Ellor, B. The removal of pharmaceuticals during wastewater treatment: Can it be predicted accurately? Sci. Total Environ. 2019, 676, 222-230. [CrossRef]

40. Schröder, P.; Helmreich, B.; Škrbić, B.; Carballa, M.; Papa, M.; Pastore, C.; Emre, Z.; Oehmen, A.; Langenhoff, A.; Molinos, M. Status of hormones and painkillers in wastewater effluents across several European states-Considerations for the EU watch list concerning estradiols and diclofenac. Environ. Sci. Pollut. Res. 2016, 23, 12835-12866. [CrossRef]

41. Boleda, M.R.; Galceran, M.T.; Ventura, F. Behavior of pharmaceuticals and drugs of abuse in a drinking water treatment plant (DWTP) using combined conventional and ultrafiltration and reverse osmosis (UF/RO) treatments. Environ. Pollut. 2011, 159, 1584-1591. [CrossRef] 
42. Sbardella, L.; Comas, J.; Fenu, A.; Rodriguez-Roda, I.; Weemaes, M. Advanced biological activated carbon filter for removing pharmaceutically active compounds from treated wastewater. Sci. Total Environ. 2018, 636, 519-529. [CrossRef]

43. Kharel, S.; Stapf, M.; Miehe, U.; Ekblad, M.; Cimbritz, M.; Falås, P.; Nilsson, J.; Sehlén, R.; Bregendahl, J.; Bester, K. Removal of pharmaceutical metabolites in wastewater ozonation including their fate in different post-treatments. Sci. Total Environ. 2021, 759, 143989. [CrossRef]

44. Elk, M.; Baresel, C.; Magnér, J.; Bergström, R.; Harding, M. Activated carbon for the removal of pharmaceutical residues from treated wastewater. Water Sci. Technol. 2014, 69, 2372-2380.

45. Yangali-Quintanilla, V.; Sadmani, A.; McConville, M.; Kennedy, M.; Amy, G. Rejection of pharmaceutically active compounds and endocrine disrupting compounds by clean and fouled nanofiltration membranes. Water Res. 2009, 43, 2349-2362. [CrossRef]

46. Soffer, Y.; Ben Aim, R.; Adin, A. Membrane fouling and selectivity mechanisms in effluent ultrafiltration coupled with flocculation. Water Sci. Technol. 2005, 51, 123-134. [CrossRef]

47. Trisaranakul, W.; Chompoosor, A.; Maneeprakorn, W.; Nacapricha, N.; Choengchan. S.; Teerasong. S. A simple and rapid method based on anti-aggregation of silver nanoparticles for detection of Poly(diallyldimethylammonium chloride) in tap water. Anal. Sci. 2016, 32, 769-773. [CrossRef]

48. Gamarra, J.S., Jr.; Godoi, A.F.L.; de Vasconcelos, E.C.; de Souza, K.M.T.; de Oliveira, C.M.R. Environmental Risk Assessment (ERA) of diclofenac and ibuprofen: A public health perspective. Chemosphere 2015, 120, 462-469. [CrossRef] [PubMed]

49. Koshani, R.; Tavakolian, M.; van de Ven, T.G. Cellulose-based dispersants and flocculants. J. Mater. Chem. B 2020, 8, 10502-10526. [CrossRef]

50. Campano, C.; Lopez-Exposito, P.; Blanco, A.; Negro, C.; van de Ven, T.G. Hairy cationic nanocrystalline cellulose as a novel flocculant of clay. J. Colloid Interface Sci. 2019, 545, 153-161. [CrossRef] [PubMed]

51. Beddow, J.; Johnson, R.J.; Lawson, T.; Breckels, M.N.; Webster, R.J.; Smith, B.E.; Rowland, S.J.; Whitby, C. The effect of oil sands process-affected water and model naphthenic acids on photosynthesis and growth in Emiliania huxleyi and Chlorella vulgaris. Chemosphere 2016, 145, 416-423. [CrossRef] [PubMed]

52. McKew, B.A.; Johnson, R.; Clothier, L.; Skeels, K.; Ross, M.S.; Metodiev, M.; Frenzel, M.; Gieg, L.M.; Martin, J.W.; Hough, M.A. Differential protein expression during growth on model and commercial mixtures of naphthenic acids in Pseudomonas fluorescens Pf-5. MicrobiologyOpen 2021, 10, e1196. [CrossRef] [PubMed]

53. Frank, R.A.; Sanderson, H.; Kavanagh, R.; Burnison, B.K.; Headley, J.V.; Solomon, K.R. Use of a (quantitative) structure-activity relationship [(Q) Sar] model to predict the toxicity of naphthenic acids. J. Toxicol. Environ. Health Part A 2009, 73, 319-329. [CrossRef]

54. Headley, J.V.; McMartin, D.W. A review of the occurrence and fate of naphthenic acids in aquatic environments. J. Environ. Sci. Health Part A 2004, 39, 1989-2010. [CrossRef]

55. Brown, L.D.; Ulrich, A.C. Oil sands naphthenic acids: A review of properties, measurement, and treatment. Chemosphere 2015, 127, 276-290. [CrossRef] [PubMed] 